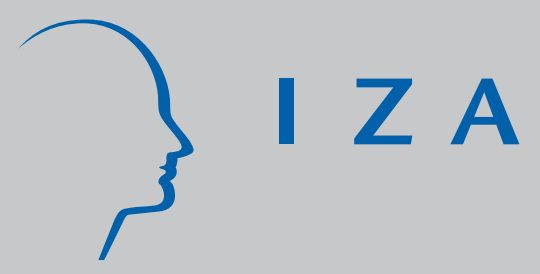

IZA DP No. 2539

The SES Health Gradient on Both Sides of the Atlantic
J ames Banks
Michael Marmot
Zoë Oldfield
J ames P. Smith
J anuary 2007 


\title{
The SES Health Gradient on Both Sides of the Atlantic
}

\author{
James Banks \\ University College London \\ and Institute for Fiscal Studies \\ Michael Marmot \\ University College London \\ Zoë Oldfield \\ Institute for Fiscal Studies \\ James P. Smith \\ RAND and IZA
}
Discussion Paper No. 2539
January 2007

IZA
P.O. Box 7240
53072 Bonn
Germany

Phone: +49-228-3894-0

Fax: +49-228-3894-180

E-mail: iza@iza.org

\begin{abstract}
Any opinions expressed here are those of the author(s) and not those of the institute. Research disseminated by IZA may include views on policy, but the institute itself takes no institutional policy positions.

The Institute for the Study of Labor (IZA) in Bonn is a local and virtual international research center and a place of communication between science, politics and business. IZA is an independent nonprofit company supported by Deutsche Post World Net. The center is associated with the University of Bonn and offers a stimulating research environment through its research networks, research support, and visitors and doctoral programs. IZA engages in (i) original and internationally competitive research in all fields of labor economics, (ii) development of policy concepts, and (iii) dissemination of research results and concepts to the interested public.
\end{abstract}

IZA Discussion Papers often represent preliminary work and are circulated to encourage discussion. Citation of such a paper should account for its provisional character. A revised version may be available directly from the author. 


\section{ABSTRACT}

\section{The SES Health Gradient on Both Sides of the Atlantic *}

Looking across many diseases, average health among mature men is much worse in America compared to England. Second, there exists a steep negative health gradient for men in both countries where men at the bottom of the economic hierarchy are in much worse health than those at the top. This health gradient exists whether education, income, or financial wealth is used as the marker of one's SES status. These conclusions are maintained even after controlling for a standard set of behavioral risk factors such as smoking, drinking, and obesity and are equally true using either biological measures of disease or individual self-reports. In contrast to these disease based measures, health of American men appears to be superior to the health of English men when self-reported general health status is used. The contradiction most likely stems instead from different thresholds used by Americans and English when evaluating health status on subjective scales. For the same 'objective' health status, Americans are much more likely to say that their health is good than are the English. Finally, feedbacks from new health events to household income are one of the reasons that underlie the strength of the income gradient with health in England.

JEL Classification: $\quad$ I10

Keywords: health, SES, labor supply

Corresponding author:

James P. Smith

RAND Corporation

1776 Main Street

P.O. Box 2138

Santa Monica, CA 90407-2138

USA

E-mail: James_Smith@rand.org

\footnotetext{
* Paper prepared for NBER conference on the economics of aging, Carefree, Arizona. The authors are grateful for the very helpful suggestions made by participants at the conference and in particular to our discussant Dan McFadden. Angus Deaton provided detailed written comments on the first draft which were very constructive. Helpful comments were also received from Meena Kumari, of UC London especially regarding the biological markers.

The expert programming assistance of Iva Maclennan is gratefully acknowledged. The English Longitudinal Study of Ageing has been supported by grants from the National Institute on Aging, US, $\mathrm{NIH}$ (2RO1AG7644-01A1, 2RO1AG017644) and several British Government departments, specifically: Department for Education and Skills, Department for Environment, Food and Rural Affairs, Department of Health, Department of Trade and Industry, Department for Work and Pensions, HM Treasury, Inland Revenue, Office of the Deputy Prime Minister and Office for National Statistics. Funding for the Health and Retirement Study was provided by grant NIA U01AG009740.

Michael Marmot is supported by an MRC Research Professorship. James Banks and Zoe Oldfield's research was supported by the National Institute on Aging through grant number ((P01 AG008291-13) with co-funding from the Economic and Social Research Council through the Centre for the Microeconomic Analysis of Public Policy at IFS (grant number: M544285003). James P. Smith's research was supported by the National Institute on Aging, US, NIH (P01 AG008291-13).
} 


\section{Introduction}

In a recent paper, we documented large differences in health status between the Americans and the English (Banks, Marmot, Oldfield, and Smith, 2006). In this paper, we extend that work by examining the relative health status of mature men in both countries. There are several advantages to limiting the focus to men. First, there are well-documented and significant health differences by gender in most countries with men experiencing worse health outcomes for certain diseases and women more likely to have other illnesses. The causes of disease may also vary by gender with work related health problems a more common cause among men and health consequences of childbirth more relevant for women. Documenting international differences by gender is important since it may shed light on the underlying reasons why these cross-country differences emerge.

An important case in point relates to the possibility of health affecting income and wealth, a pathway that is undoubtedly more relevant for men than for women in both the US and England, at least for current cohorts approaching retirement. Of those currently ten or so years before retirement, men will have had much higher levels of labor force activity than women. A new serious health event that takes place during that time may well trigger labor force exits before the planned retirement age. If income replacement is not complete, these labor force withdrawals will also be associated with lower household incomes and wealth.

The strength of this pathway has already been established in recent research on the United States (Smith, 1999, 2005), but little is known about its importance in other countries, including England. One advantage of selecting these two countries is that England has set up institutional arrangements whose goal is to isolate individuals from the economic consequences of poor health not only in terms of any medical expenditures they may have to pay. While by no means complete, a similar argument applies to earnings and job losses, where social insurance in the UK is also arguably more generous. The more generous income maintenance system in the UK should mitigate any effects that adverse health changes may have on income and wealth there compared to the US.

In this paper, we will investigate the size of health differences that exist among men in England and the United States and how those differences vary by SES in both countries. Three SES measures will be emphasized —education, household income, and household wealth—and the health outcomes investigated will span multiple dimensions as well.

International comparisons have played a central part of the recent debate involving the SEShealth gradient. For example, Wilkinson (1996) cited cross-country differences in levels of income equality and mortality as among the most compelling evidence that unequal societies have negative impacts on individual health outcomes. In spite of the analytical advantages of making such international comparisons, until recently good micro data measuring both SES and health in comparable ways have not 
been available for both countries. Fortunately, that problem has been remedied with the fielding of two surveys - the Health and Retirement Survey (HRS) and the English Longitudinal Survey of Aging (ELSA). In order to facilitate the type of research represented in this paper, both the health and SES measures in ELSA and HRS were purposely constructed to be as directly comparable as possible.

Since income and wealth inequality are greater in the US than the UK, Wilkinson's argument would imply poorer health outcomes among those at the bottom in the US and a steeper social health gradient in the US compared to the UK. If differences in social hierarchies are greater in the US than in UK, whether driven by income inequality, social stratification in the workforce, or other forms of ranking where degree of difference matters, the theories of Wilkinson and Marmot (1999) tend to imply steeper SES gradients in the US. Similarly, if one sees the US as a more competitive winner-take-all system with lower levels of social support in the community and state, theories that emphasize negative impacts of psychosocial stress on those at the bottom also point to steeper US health gradients compared to those in England.

This paper is divided into nine sections. The next describes the two primary data sources that will be used in this analysis. Section three highlights the most salient aspects of the male SES health gradients in self-reported diseases in both countries, emphasizing both their similarities as well as their differences. Section four documents the very different portrait of across-country differences in health that is obtained when self-reported general health status is used instead as the primary health status measure. The fifth section documents that these differences in male health in the two countries are not due to standard behavioral risk factors, such as smoking, drinking, and obesity. Section 6 explores the degree to which differential measurement of self-reports of health status between the two countries accounts for the differences that emerge in the SES health gradient. The issue of the relevance of absolute and relative income scales to make international comparisons is addressed in section seven. Section eight explores whether there are important health affects on male labor force activity and household income in England and the ninth section examines health gradients by financial wealth in the two countries.

\section{DATA}

This research will initially rely on four important surveys from the two countries, each designed to contain comparable measures of both SES and health outcomes.

\section{Health and Retirement Survey}

For the United States, our research will be based on a combined set of cohort surveys of the overage 50 populations in the United States—-the original Health and Retirement Study (HRS), the Assets and Health Dynamics of the Oldest Old (AHEAD), the Children of the Depression Age (CODA), and the 
War-Babies Cohort. ${ }^{1}$ The objective of these surveys is to monitor economic transitions in work, income, and wealth, as well as changes in many dimensions of health status among those over 50 years old.

In these surveys, questions were included on demographics, income and wealth, family structure, and employment. Questions were asked in each wave about self-reports of general health status, the prevalence and incidence of many chronic conditions, functional status and disability, and medical expenditures. Other related health variables include depression scales, health insurance, smoking, physical exercise, weight and height (so that BMI can be calculated). No clinical measures of health are currently available in the HRS.

To be comparable with the ELSA survey, which was fielded, in the same year, we use the 2002 wave of these combined surveys, which we will refer to as HRS02. Thus, HRS02 is representative of all birth cohorts born in 1947 or earlier who will be 54 and over in that year. To insure that any differences between the countries that emerge are not due to special issues that exist in the African-American or Hispanic communities in the Unites States, the American data presented here exclude those two populations.

\section{National Health and Nutrition Examination Survey (NHANES)}

Since clinical measures will form part of the evidence presented here and these are not available in the HRS, we turned instead to the most recent National Health and Nutrition Examination Survey (NHANES), which were fielded between 1999 and 2002. NHANES contains data obtained through personal interviews, physical and lab exams (blood, urine, and swabs) for people two months and older. Information is available on the self-reported prevalence of a wide variety of illnesses, and individual characteristics including age, gender, race, marital status, household income (in brackets) and education. In addition, physical exams and laboratory measurements were performed on respondents so that clinical prevalence of disease can be calculated. While NHANES is a nationally probability sample of the noninstitutionalized civilian population, African Americans and Latinos were severely over-sampled.

NHANES 1999-2002 contains 21,004 interviews with medical exams on 19,759 respondents. To maintain comparability with our previous data from HRS, African-Americans and Latinos are excluded from the analyses that follow. In addition, we mostly limit our samples to two age groups-55-64 for comparability with HRS and those ages 40-70. Sample sizes for the age group 55-64 are too small except for the most basic description. All data based on the NHANES are weighted.

\footnotetext{
${ }^{1}$ HRS is a national sample of about 7,600 households (12,654 individuals) with at least one person in the birth cohorts of 1931 through 1941 (about 51-61 years old at the wave 1 interview in 1992). AHEAD includes 6,052 households (8,222 individuals) with at least one person born in 1923 or earlier (70 or over in 1993). In 1998, HRS was augmented with baseline interviews from the cohorts of 1924-1930 (the CODA cohort—2320 individuals) and 1942-1947 (the War Babies—2529 individuals).
} 


\section{English Longitudinal Survey of Aging-ELSA}

In ELSA, around 12,000 respondents from three separate years of the Health Survey for England (HSE) survey were recruited to provide a representative sample of the English population aged 50 and over on February 29, 2002. A major advantage of HSE sampling is that baseline data on respondents' health (details of morbidity, lifestyle, diets, and blood samples) had already been collected. The health data was supplemented by collection of baseline social and economic data in the first wave of ELSA. Future rounds of ELSA, to be fielded every two years, will track changes in health and economic position.

Like HRS02, ELSA is quite strong in measurement of various dimensions of SES. Detailed education data, employment, income, wage, and asset modules have been fielded and the quality of the baseline data appears to be quite high (Marmot et al. 2003). In particular, those who keep their finances separate are separately asked about their incomes and assets, whereas for those with jointly held income, assets, and debts a financial respondent provides information on behalf of the couple. This section of the questionnaire is modeled closely on the HRS, adopting many of its innovations such as the use of unfolding brackets to minimize non-response.

ELSA is especially rich in the health domain. Its health module collects data on self-reported general health, specific diagnoses of disease (hypertension, heart disease, diabetes, stroke, chronic lung diseases, asthma, arthritis and osteoporosis, cancer, and emotional and mental illness including depression, memory and cognitive assessment, disability and functioning status (e.g., ADLs and IADLs), difficulty with pain, health behaviors (smoking, alcohol consumption, and physical activity), and symptoms of heart disease (dizziness and chest pain (the Rose Angina Questionnaire)). While certainly not identical, many of these modules closely parallel those available in HRS.

Health measurement in ELSA is arguably superior to that available in the American counterpart. Advantages include the prior physical measurement (blood samples, waist, height, hip, blood pressure) and respondent health measurement available in the Health Survey for England from which the ELSA sample was drawn. Moreover, wave 2, which was carried out in 2004/5 comprised a further face-to-face interview with nurse visits that repeated the HSE measurement of biological markers, collected additional biological samples (fasting bloods, cortesol) and included a further battery of physical functioning tests (grip strength, balance test, chair stand, lung function test). Further nurses' visits are planned for every second wave and the walking speed test is intended will be repeated as part of the core ELSA interview every two years.

The biological measures are of interest for several reasons. They include markers such as fibrinogen (which controls blood clotting and is a risk factor for CVD), HbA1c (a test for diabetes), Creactive protein (CRPC-measuring the concentration of a protein in serum that indicates acute 
inflammation and possible arthritis), and cholesterol. Such measures can be used not only to validate respondents' self-reports and to gauge overall health, but they can inform us about pre-clinical levels of disease of which the respondents may not have been aware and therefore to which they have not yet able to react behaviorally. The pre-clinical gradient in disease is a largely unexplored area of research in large population based samples.

\section{Health Survey for England (HSE)}

For the purposes of this paper, clinical measures for England were obtained from the 2003 Health Survey for England (HSE), which is part of an annual survey monitoring health. ${ }^{2}$ The 2003 HSE is a survey of 18,553 respondents of all ages, including children. For the purposes of this analysis we draw similar age sub-samples to those described above for those aged between 40 and 70 . The survey protocols included an interview visit followed by a nurse visit where saliva and blood samples were drawn. Hence, all analyses are weighted using weights designed to control for sample design and aggregated nonresponse into the nurse visit section of the HSE interview. The blood samples collected at this nurse visit were analyzed for total and HDL cholesterol, fibrinogen, C-reactive protein, and glycated hemoglobin. Respondents were also asked to self-report on any diseases they may have. The 2003 HSE placed special emphasis on cardiovascular disease and the behavioral risk factors associated with cardiovascular disease such as drinking, smoking and eating habits. The survey also covered health status risk factors such as blood pressure, cholesterol and diabetes. ${ }^{3}$

\section{ESTABLISHING THE FACTS-THE NATURE OF THE GRADIENT IN THE UK AND US}

In this section, we present some basic descriptive statistics that contrast the shape of the SES health gradient in these two countries. The health gradient is first defined across two of the more widely used dimensions of SES-years of schooling and family income. These two dimensions of SES may capture quite different reasons for the origin and existence of the gradient. In the United States, education is separated into three groups: $0-12,13-15$, and 16 or more. We experimented with different education classifications in the UK in order to engender comparability although the resulting classification inevitably involves some inherent stance about the nature of education in each of the two countries. In the end we use the following three way division: qualified to a level lower than "O-level” or equivalent (typically 0-11 years of schooling), qualified to a higher level but lower than “A-level” or equivalent

\footnotetext{
${ }^{2}$ Although we also have biomedical information for those ELSA respondents who were originally sampled in the 1998 HSE the use of the more recent year of data provides us with a wider array of biomedical measures and a larger sample. In addition the comparison to the recent years of NHANES is more contemporaneous.

${ }^{3}$ For more details, see Health Survey for England 2003-Methodology and Documentation—Series HS Number 13.
} 
(typically 12-13 years of schooling) and a higher qualification (typically more than 13 years of schooling).

Constructing income groups is more straightforward. In both countries, family income is adjusted for household size using the OECD equivalence scale, and divided into three age specific income terciles. To insure that the observed patterns are not confounded by variation in either SES or health by age, our comparisons are restricted to those who are 55-64 years old.

Even more so than SES, there are a multitude of possible measures of health status. Among others, these would include the existence and severity of an assortment of physical and emotional diseases, the ability to function effectively in workplace, home, and other important every day settings, and self-assessments of more general health status.

Table 1 lists the fraction of men ages 54-64 reporting specific diseases where the data are stratified by income terciles and by years of schooling. A separate panel exists for the following seven diseases — diabetes, hypertension, all heart disease, heart attacks, strokes, cancer, diseases of the lung, and cancer. We next present short summaries of the major patterns that emerge for each disease.

\subsection{DIABETES}

Our comparisons begin with diabetes. Diabetes is a disease in which the body does not produce or properly use insulin, a hormone required to convert sugar into energy. Both genetics and environmental factors such as obesity and lack of exercise appear to increase risks of being a diabetic. Type 1-diabetes results from a failure of the body to produce insulin while the far more common Type 2 diabetes results from an inability of the body to properly use insulin.

For men, overall prevalence rates of diabetes are twice as high in the US (14.4\%) compared to those in England (7.1\%). There is a steep negative gradient across income terciles as we move from the lowest to the highest income groups in each society. This income gradient is much sharper in the US so that the disparity in diabetes prevalence between the countries expands as we move down the income scale. For example, in this age group, rates of male diabetes are 12 percentage points (around 150\%) higher in the US in the lowest income tercile compared to only 4 percentage points (around 80\%) higher in the highest income tercile. One in every five American men among those in the lowest income class in this age range is a diabetic.

The two countries are more distinct across education groups where the gradient is quite steep and negative in the United States but less pronounced in England. The net result is that when we compare the 'bottom of the bottom'-those simultaneously in the lowest education group and the lowest income quintile - to those respondents at the 'top of the top'-those simultaneously in the highest group in both measures of SES - the disparities between both countries are maximized. For example, within the joint 
lowest education-lowest income tercile grouping, 23\% of American men report having diabetes compared to 9\% of English. In contrast, within the 'top of the top', the comparable data indicate a difference of about five percentage points between men in the two countries (11\% compared to 6\%).

This contrast between the dual education-income SES extremes in both countries will receive some emphasis in our ongoing summary of the comparative nature of the health gradient. And at least for diabetes, the data appear to show that in a within country comparative sense Americans who rank in the lowest SES echelons are in worse health than their British counterparts at the bottom of the British SES hierarchy. But this is not simply an issue of the social health gradient. American men in the highest income-education class have higher diabetes prevalence (11\%) then English men in the lowest educationincome class (9\%). Those at the bottom of the SES hierarchy are at greater risk of being diabetic in America and England but there is a substantial higher risk, independent of SES, in the US compared to England.

\subsection{HYPERTENSION}

Respondents in both ELSA and HRS were asked if a doctor have ever told them if they had high blood pressure. Hypertension (high blood pressure), a major risk factor for cardiovascular disease (CVD), is a relatively common condition, especially for men, with a prevalence that grows rapidly with age. Before the introduction of new effective drugs, the recommended treatment consisted of some combination of exercise and diet, particularly to reduce excessive weight and salt.

In many ways, the cross-national patterns for prevalence of high blood pressure (HBP) mirrors those just documented for diabetes. Overall male prevalence is considerably higher in the US-a difference of about 12 percentage points (46.8\% in the US compared to $34.4 \%$ in the UK). Negative gradients exist across education and income in both countries with indications of a slightly steeper education and income gradient in US. The net result is that differences between the two countries are once again largest at the "bottom of the bottom" of the SES hierarchy compared to the "top of the top."

\subsection{HEART DISEASE}

Coronary heart disease (CHD) is one of the leading causes of human mortality especially among men. Disease disparities by SES in CHD have attracted increased research attention in recent years in part because the SES disparities are so large. In addition, recent research has suggested that psychosocial factors including many that are economic in origin may offer important clues about some of the underlying causes of these differentials (Steptoe and Marmot, 2005).

Table 3 shows that coronary heart disease is far more common among American men compared to English men in this age range. Overall prevalence is about six percentage points higher in the United 
States. As has been documented in many studies (see Steptoe and Marmot, 2005), there are very pronounced gradients in heart disease across both education and income groups. These gradients characterize both countries leaving substantially higher risks for the underclass in both countries.

\subsection{HEART ATTACKS}

Our attention now shifts to a far more serious form of CVD—having had a heart attack in the past. Overall prevalence among men remains somewhat higher in the US (8.0\%) than in England (6.3\%). Negative SES health gradients are still the order of the day in both countries but the gradient across income is decidedly steeper than it is across years of schooling. Since both absolutely and relatively the income gradient is steeper in the United States, inter-country differences in prevalence are maximized when the comparison centers on the 'bottom of the bottom.' The American male rate of heart attacks exceed British rates by 4.8 percentage points at the bottom of the bottom compared to only six tenths of a percentage point at the top of the top.

\subsection{STROKE}

Stroke occurs with the sudden death of some brain cells due to a lack of oxygen impairing the blood flow to the brain by blockage or rupture of an artery to the brain. We find very similar patterns for strokes as reported above for heart attacks. Male prevalence rates are slightly higher in US than in England (4\% vs. 3\%). Sharp negative gradients persist across both education and income in both England and the United States so that those at the 'bottom of the bottom' face the larger prevalence risk in both countries. In England, the risk of having had suffered a stroke is four times larger at the 'bottom of the bottom' compared to those at the 'top of the top'. The comparable relative risk differential in the United States is almost nine to one. Consequently, the biggest disparities between the two countries clearly lie within the 'bottom of bottom' (7.0\% compared to 5.3\%) while at the 'top of the top' prevalence is actually somewhat lower among American men (0.8\% compared to 1.3\%).

\subsection{DISEASES OF THE LUNG}

Lung disease, an impairment or disorder that impairs the function of the lungs, is one of the leading causes of death in both England and the United States. There are several forms of lung disease but a common separation involves obstructive and restrictive lung disease. Obstructive lung diseases, such as emphysema, bronchitis, or asthma, cause a narrowing or blockage of the airways resulting in decreased exhaled airflow. Restrictive lung disease involves a decrease ability of the lung to expand and to transfer oxygen to the blood. Lung disease is a useful addition for international comparisons since the root causes 
are believed to be quite different than the other diseases that we have examined. Smoking and a variety of indoor and outdoor pollutants are believed to be the major reasons for lung diseases.

In spite of these quite different root causes, Table 1 demonstrates that diseases of the lung also exhibit similar cross-country differentials and within country patterns although the scale of the overall differences between the two countries is reduced — the higher prevalence rates in America are 6.8\% compared to 5.8\% in England. Sharp income and education gradients exist in both countries, with a much steeper income gradient in US. The contrast at the extremes of SES mimic the findings for the other diseases that we have examined-much larger across country disparities to the disadvantage of American men among those at the very bottom SES tier compared to those at the very top.

\subsection{CANCER}

Cancer prevalence among men is much higher in the US, with a surprisingly large difference between the two countries (7.3\% compared to 3.6\%). In sharp contrast to all other diseases that we examined, the SES gradient in cancer prevalence is almost non-existent across either education or income. There are two factors that make reliance on cancer prevalence alone to characterize health status across groups or countries more problematic. Given the how serious the illness is, the SES gradient with cancer may be affected by both differential diagnosis and differential mortality. In either country, those in lower SES groups may be unaware that they have cancer or be at greater risk of dying quickly from their cancers, thereby camouflaging the true nature of the incidence and prevalence across different SES groups. Since screening rates for cancer are in general thought to be higher in the USA than in England, this may also play a role in the higher rates of cancer in the US, as may greater incident mortality from cancer in England (Melia and Johns, 2004 or Sirovich et al., 2003).

These issues certainly require more investigation. However, the magnitude of these cross-country differences in cancer prevalence appears to us too large to be fully explained by these factors alone. Differences in cancer prevalence between England and the US also exist in the high education and income groups where differential detection and incident mortality should play a weaker role. For example, the differences in cancer prevalence are quite large for those at the 'top of the top', those individuals in both countries who are simultaneously in the highest education group and highest income tercile. In that group, prevalence among American men is 7.7\% compared to 3.5\% among Englishmen. These higher rates of American cancer prevalence are similar to those at the 'bottom of the bottom.'

Whatever the causes for the higher cancer prevalence in the United States, the absence of any social gradient in the disease in either country suggests that these reasons may be quite different than those producing higher rates of American illness in the other diseases we have examined. 


\section{INTERNATIONAL COMPARISONS USING GENERAL HEALTH STATUS}

In the previous section, we have compared disease prevalence rates of men between the ages of 55-64 in two countries-England and the United States. Our comparisons included many different types of diseases that together would account for most of human mortality. Two clear messages flow from these comparisons-Americans men are much less healthy than English men of the same age and there exists a very dramatic social gradient in health across most of these diseases using either education or income as the marker of one's SES group. These conclusions confirm findings obtained in our recent study that considered all adults as opposed to men and women separately (Banks, Marmot, Oldfield, and Smith, 2006).

Before moving on to try to discuss potential explanations for these results, it is necessary to highlight an apparently stark contradiction to our findings. A frequently used measure of health status especially for international comparisons - is to use individuals' self-evaluation of their overall health. A standard metric relies on a five-point scale-excellent, very good, good, fair and poor, a scale that was included in both HRS and ELSA. To simplify without losing its main attributes, we converted that scale into two dichotomous outcomes - good health (answers of 'excellent' or 'very good') and bad health (answers of 'fair' and 'poor') with those answering simply 'good' falling into neither category.

Table 2 lists the fractions of American men and English men who are in good health and in bad health according to this definition. In spite of the fact that disease prevalence rates are higher in America than in England, and sometimes considerably so, for every disease included in Table 1, using selfreported health scales American men rate themselves as healthier than their English counterparts. Nor are the differences between the two countries trivial-the proportion of English men reporting bad health is eight percentage points higher than it is in the US. Controlling for education or income does not eliminate the contradiction-in every education-income cell in Table 2, a higher fraction of American men report good health than do their English counterparts.

The puzzle using general health status scales extends to its description of the gradient as well. While reports of good health in both countries increase with education and income, the relative magnitude of the gradient actually appears steeper in England, the reverse of the ordering of the two countries when we examined specific diseases in Table 1. To illustrate, 51\% of English men between the ages of 55-64 who are at the 'bottom of the bottom' claim that their health is 'bad' compared to $13 \%$ of English men at the 'top of the top.' The comparable numbers among American men are $40 \%$ and $10 \%$ respectively so that the across country disparities are once again maximized at the 'bottom of the bottom,' but in this case it is to the disadvantage of English men within the lowest SES tiers.

The apparent contradiction between these two standard measures of health status - self reported disease prevalence and self-reported health status_-for international comparisons raises questions of 
which of the two provides the more reliable index and why the contradiction exists in the first place. One possibility is that the self-reports of disease are incorrect in their ranking of the two countries by disease. However, we will provide evidence in section six using biological measures of disease that the disease prevalence self-reports are in fact not incorrect - one obtains the same image of Americans being sicker than the English using biological measures of disease.

A possible reconciliation of the two disparate portraits of relative health in the two countries is that we have only examined physical health in Table 1. Self-reported general health status may be more sensitive to emotional and psychological aspects of health. To investigate this, Table 3 lists the fraction of men between ages 55-64 who say that they have emotional problems. But even along the emotional dimension of health, American men appear to be worse off then English men are and these differences are just as large as those documented for physical health in Table 1. The sharp negative social gradients in health also appear in the emotional domain for both education and income in both countries.

Another possible reconciliation may lie in differential rates of co-morbidity in the two countries. Even though prevalence rates for individual diseases may be lower in England than in the United States, those individuals who are sick with one disease in England may simultaneously be ill with other diseases leading them to self-report their health status as bad. However, the second panel of Table 3, which shows rates of prevalence of two or more diseases from the set analyzed in table 1 amongst those with at least one illness, demonstrates that co-morbidity rates are also higher in America than in England.

The next factor we examine in Table 3 is whether differences in functional limitations can explain the tendency of Englishmen to self-report themselves in poorer health. Although other domains of functional limitations and disability can and should be analyzed the one we measure here is self-reported mobility limitations. Table 3 lists the fraction of male respondents in each country who report at least one limitation from the following set: walking a block, sitting for about two hours, getting up from a chair after sitting for long periods, climbing a flight of stairs without resting, stooping kneeling or crouching, reaching or extending arms about shoulder level, pushing or pulling large objects such as a living room chair, lifting or carrying weights over 10 pounds, picking up a dime from a table. Once again, even using a relatively broad level of disability, we find that Americans experience more difficulty than the English do.

With all these possible reasons eliminated, the reason that self-reported general health status may provide an incorrect portrayal of the overall health status in the two countries must lie elsewhere. On possibility is simply that there are omitted factors along the lines of those we have considered above which affect subjective general health. Alternatively, there may well be problems with using subjective scales for international comparisons. A growing number of studies have documented that residents of different countries even when their health is identical use different thresholds when self rating their own 
health (King et al. (2003); Kapteyn, Smith, VanSoest (2004)). In particular, this research demonstrates that Americans are relatively optimistic when evaluating their health status given the objective circumstances. For the same 'objective' health circumstances, Americans are more likely to rate their health as good than residents of other countries are. Moreover, the use of different thresholds can confound the evaluation of health across SES groups even within the same country if the threshold standards vary by SES as well. ${ }^{4}$ As a result of these problems, we conclude that using self-reported health scales will not be useful in making comparisons about the nature of the SES-health gradient in the two countries.

Two further comments are in order. Firstly, if international comparisons of subjective general health measures yield results that depend on differential reporting behavior across countries then the analysis of such measures within national populations may also be thought to be somewhat dependent on the same type of reporting differences, to the extent to which they arise across socioeconomic groups. Such an issue is not investigated here but left as an important topic for future research. Second, our discussion above should not be taken to diminish the interest in subjective general health measures. In a similar way in which one can argue individuals subjective economic expectations are important to measure and study, regardless of whether they reflect the true underlying nature of economic processes, when thinking about attitudes to health and in particular willingness to undertake particular health behaviors such as improved diet, increased exercise or reduced smoking and drinking, an individual's subjective perception of their own health state, and the particularly benchmarks they use to rate it, may well be important.

\section{RISK FACTORS AND THEIR ROLE IN THE GRADIENT}

It is standard practice in epidemiological studies to relate the prevalence or incidence of disease to a relatively small set of risk factors that make having the disease more likely. For diabetes and heart disease, these risk factors typically include smoking and drinking behavior, and obesity, concepts that can be comparably defined in ELSA and HRS. Using the same format as above with cross stratifications by education and income terciles, Table 4 lists among men ages 55-64 in both England and the US average rates of smoking, obesity, being overweight, and heavy drinking (defined as drinking on more than 4 days per week in HRS and twice a day or more/daily or almost daily in ELSA).

On average, male smoking behavior is remarkably similar in both countries with about one in five people in this age group currently smoking. Strong negative gradients across income and education exist in both countries, but these gradients appear somewhat steeper in England compared to the United States.

\footnotetext{
${ }^{4}$ SES health gradients characterize the health gradient in this measure as well. Reports of good health rise with both education and income and reports of bad health decline fall in both countries.
} 
Thus differential male smoking behavior by itself not only cannot explain the higher concentration of disease (particularly those related to smoking) at the lower rungs of the joint SES classification in America. In fact, it actually deepens the mystery by making the adjusted differentials that much higher in America compared to England.

Obesity (defined as BMI greater than 30) is a risk factor for a number of diseases including heart disease and diabetes. In both countries, male rates of obesity decline with income and with education both unconditionally and after conditioning on the alternative SES measure. Especially along the income dimension of SES, differences between the two countries are largest in the lowest income tercile. Among those in the lowest income tercile, male obesity rates are thirteen percentage points higher in the US while they are only six percentage points larger in the highest income tercile.

Finally, there are higher rates of heavy drinking among men in England than in the United States. Since heavy drinking is more common among those at the top of the education and income strata, it is also an unlikely explanation for the concentration of disease among those at the bottom in either country, although more moderate drinking in high SES groups could contribute to lower heart disease risk.

This short summary suggests that collectively these behavioral risk factors cannot explain either one of our two main conclusions- the lower health status among American men compared to English men and the strong negative health gradient across both education and income groups in both countries.

To more precisely evaluate this, we estimated a set of OLS on the prevalence of all of diseasesdiabetes, hypertension, heart attacks, stroke, arthritis, lung disease, and cancer. These models included the three education groups, and three income quintiles used in the SES stratification in Table 1, and measures of the following risk factors (obesity, overweight, smoking, and excess drinking). By and large, the set of risk factors included in the analysis perform in the expected direction. For example, being obese and overweight is associated with higher rates of diabetes, hypertension, heart attacks, stroke, arthritis, and lung disease and being a current smoker is strongly associated with lung disease and stroke. While not presented here, the inclusion of these standard set of risk factors and SES measures such as income and education at best can explain only $20-30 \%$ of the overall difference in male health status between these two countries. They also fail to explain much of the social gradient in health (see Banks et al (2006)). The major explanations therefore must lie elsewhere.

\section{DIFFERENCES IN REPORTING HEALTH OUTCOMES ACROSS THE ATLANTIC}

Whether one uses prevalence of specific illness or general health status as the health outcome measure, our description of comparative health conditions in England and America thus far relies completely on respondent self-reports. We have already showed that self-reported conditions and selfreported general health give qualitatively different pictures of health differences between America and 
England, potentially rendering the use of self-reported general health scales for international comparisons problematic.

Even if we confine ourselves to disease prevalence, self-reports are known to have several potential problems. Diseases may be unreported due to limited contact with the medical system and even when previously diagnosed, individuals may confuse having the disease under control with it being cured. If those within lower SES groups are less likely to report a health problem that they actually have, these reporting problems may have a SES gradient of their own. For our purposes, however, the key issue is whether or not differential reporting of health problems especially by SES differs between England and America. Protocols and thresholds for specific disease diagnosis may not be the same in the two countries so that a similarly ill patient may be diagnosed with the disease in one country but not the other.

One way of addressing how important this issue is to examine biological markers of disease in both countries. There are two related questions we will ask using biological markers: (1) are the disease patterns by SES using clinical indicators of disease similar to those obtained with respondent self-reports in both countries; and (2) are any of the most important cross-country differences that we have identified using self-reports due to differential reporting of illness between the two countries? In a recent paper (Banks et al, 2006), we demonstrated that biological markers confirmed the conclusion of higher rates of disease in the United States compared to England. In this section, we examine a set of biological markers to assess the extent to which that conclusion remains true for men.

\section{Diabetes}

All participants ages 12 and over in NHANES and the HSE were evaluated for diabetes with a glycosylated hemoglobin A1c (HbA1c) test. This test records average blood glucose over a period of two or three months (the number of glucose molecules attached to hemoglobin, a substance in red blood cells). While there is no strict diagnosis threshold value, we will initially follow the American convention by using values greater than or equal to $6.5 \%$ as indicating clinical diabetes. Although not usually a screener for diabetes, HbA1c is highly correlated with fasting plasma glucose levels.

Table 5.A illustrates the correspondence between male respondents' self-reports on whether a doctor had told them they had diabetes and those based on the HbA1c values among those 55-64 years old in NHANES and in the HSE. In both countries, diabetes prevalence based on the two measures is actually very similar (in the US $10.9 \%$ for self-reports and $10.5 \%$ for clinical while the corresponding measures in England are $6.8 \%$ and $6.3 \%$ respectively). Similarly, in both countries the vast majority of men are similarly labeled on both self and clinical reports (US=95.2\%; England=95.9\%). By far, the most important pattern in Table 5.A confirms that whether one uses self or clinical reports diabetes prevalence among men is much higher in the United States than it is in England. 
The convention in the health field (at least in the US) is to call those above the clinical threshold who do not self-report diabetes the 'undiagnosed population'. In this age group in the US, there are $2.5 \%$ such men, implying an overall diabetes prevalence of $12.6 \%$, or equivalently that $20 \%$ of male diabetes in this population is undiagnosed. In England, the group above the clinical threshold who do not self-report as diabetics constitutes $2.3 \%$ of men in this age group, a rate of undiagnosis of $28 \%$, which would raise overall prevalence there to $8.6 \%$. Accepting these sorts of calculations at face value would not alter our basic finding that male diabetes is a far more serious problem in America compared to England.

However, there are also men who claim that that they are diabetics but who fall below the clinical threshold. The convention in the health field apparently is not to allow false positives, arguing that medication or insulin is likely to have placed them below the threshold. Not allowing any offset is surely too extreme since we know in panel surveys like the HRS some respondents negate their prior self-reports of diabetes in subsequent rounds. Since this is not our central concern, we will not also allow any offsets. ${ }^{5}$ It is worth noting that this subset of the male population is somewhat higher in the US than in England (2.5\% compared to 2.3\%). This could reflect better management and adherence to medical regimens in the United States.

Rates of undiagnosed diabetes in the United States is 20\% and in England 28\%. Using NHANES II, which covered the period between 1976-1980, self-reported diabetes prevalence for all whites between ages 55-64 was 6.0\% while the undiagnosed rate was 5.9\%. Similarly, data from NHANES III (19981994) show that about one-third of people with diabetes are unaware they have diabetes because their diabetes has not been diagnosed (Harris et al. (1998)). Based on the current waves of NHANES, undiagnosed diabetes is apparently much less of an issue today in the US than in the past. This means that the widely cited growth in reported diabetes prevalence may be overstated. It also raises the possibility that some part of higher contemporaneous prevalence in the US compared to England could have resulted from lower rates of undiagnosed disease in America if England did not share in this rapid secular decline in undiagnosed disease. This possibility however is soundly rejected by our data.

In addition to overall rates of undiagnosed disease, our primary interest centers on how clinical and self-reports differ by SES. Table 5.B facilitates this comparison by listing for both countries male prevalence rates by self and clinical reports by education and income groups and, in the final column, the percent who are undiagnosed diabetics. Due to sample size consideration in NHANES, the age group in this comparison is expanded to those male White Non-Hispanics between ages 40-70. A similar age restriction is imposed on the English sample.

\footnotetext{
${ }^{5}$ For example $40 \%$ of those $25-70$ years old in NHANES who self-reported that they had diabetes but were clinical below the threshold were not taking either insulin or medication. Similarly, $60 \%$ of those who self-reported that they had HBP but who were clinically below the threshold were not taking medication, reducing salt, exercising more, or reducing alcohol, or controlling their weight to reduce their hypertension.
} 
This table supports three conclusions. First, there is a strong SES gradient to male diabetes prevalence in both countries whether self-reports or clinical measures are used. Second, the gradient is even stronger for education using the clinical criteria. Third, and as a direct corollary, rates of undiagnosed diabetes are higher among those at the bottom of the education hierarchy. For example in the United States, among those in the lowest education category, the percent of men with undiagnosed diabetes is $31 \%$. The comparable numbers for those men in the highest education and income group is a $19 \%$ rate of undiagnosed diabetes. In each education cell, rates of undiagnosed diabetes are higher in England than in the United States.

While the 6.5\% threshold used in Table 5.A represents the conventional American diagnostic threshold, some have argued that the standard threshold in England is 7\%. Higher clinical thresholds are a possible explanation for the lower rates of both clinical and self reported diabetes there. To check on this possibility, Table 5.C replicates Table 5.A except that a clinical threshold of 7\% is used instead of 6.5\%. While diabetes prevalence rates are necessarily lower, the two tables are virtually identical in their message on across-country differences, indicating that there simply is not sufficient density around these thresholds to alter our conclusions by much.

\section{High Blood Pressure}

In NHANES and HSE as well as HRS and ELSA, self-reports of hypertension are based on a question of whether or not a physician has informed you that you have high blood pressure or hypertension. For the clinical definition, we follow the recommendations in the Sixth Report of the Joint National Committee on the Prevention, Detection, Evaluation and Treatment of High Blood Pressure (1997)-systolic blood pressure equal to or greater than $140 \mathrm{~mm} \mathrm{Hg}$ and/or diastolic blood pressure equal to or greater than $90 \mathrm{~mm} \mathrm{Hg}$ and/or taking medication.

Using NHANES and HSE, Tables 6A and 6B provide a comparison between self and clinical reports for HBP using the same format employed above for diabetes. Once again among male respondents between the ages 55-64 years old, in the vast majority of cases (84\%), the average diagnosis rate is the same using either the self or biological criteria. The rate of undiagnosed hypertension in this age group is $21 \%$. Similar to diabetes, there has also been a steady secular decline in "undiagnosed hypertension in the United States.” According to the CDC website on Health People 2010, “Comparing the 1976-80 National Health and Nutrition Examination Survey (NHANES II) and the 1988-1991 survey (NHANES III, phase 1) reveals an increase from $51 \%$ to $73 \%$ in the proportion of persons who were aware that they had high blood pressure.”

However, five percent of respondents say that they have HPB although their clinical readings claim otherwise. This group represents some unknown amalgam of the presence of false positives or 
individuals who may be controlling their HBP through means other than medication. Both clinical and self-reports of hypertension indicate a very strong SES gradient across either income or education. ${ }^{6}$ However, in contrast to diabetes, the percent of individuals who are undiagnosed with HBP does not appear to rise with either dimension of SES, and if anything it may increase slightly.

The three remaining clinical measures that we examine are C-reactive protein, fibrinogen, and cholesterol. In these cases, there is no matching respondent self-reports so the primary issue becomes whether the nature of the gradient and the differences across countries are similar to those obtained for self-reports on diseases for which these clinical measurements are well-established risk factors. This will include in particular cardiovascular disease and to a lesser extent arthritis. Table 7 lists data for men for all these biological markers where the stratifying SES variable is education. A similar format is used in Table 8 using family income terciles as the SES marker.

\section{C-Reactive Protein}

C-reactive protein (CRP) is an acute phase reactant released in response to acute injury, infection, or other inflammatory stimuli. Plaques in diseased arteries quite often contain inflammatory cells and the release of acute phase reactants in response to this type of inflammation have been proposed as a marker for arteriosclerosis. Several studies have shown a positive association between C-reactive protein and coronary artery disease and that it serves as a good marker for future cardiovascular events (Mendall et al. 1996).

C- reactive protein measures the concentration of a protein in serum that indicates acute inflammation and possible arthritis. Tests for C-reactive protein were conducted on respondents in NHANES and the HSE. Once again, we will be following convention by categorizing measurement into three groups “ $3 \mathrm{mg} / \mathrm{L}$ ” or higher indicates high risk, between " 1 ” and “ 3 ” is moderate risk, and less than " 1 ” is low risk.

There are several quite striking patterns. First, male levels of C-reactive protein are higher in the US than in England. To illustrate among those 40-70 years old, 33\% of American men have levels placing them within the high-risk group compared to only 28\% of English men of the same age. Secondly, health gradients are clearly alive and well in both countries for both education and income using C-reactive protein. In the US for example, $47 \%$ of those in the lowest education group are at high risk compared to $28 \%$ of those in the highest schooling class. In England, the comparable numbers are $36 \%$ and 23\% respectively. Across both the income and education dimensions, there appears to be a somewhat steeper gradient in the United States compared to England.

\footnotetext{
${ }^{6}$ Note that there is a difference in the ranking of the two countries in hypertension prevalence in using HSE and ELSA as the source. The reasons for this discrepancy are not apparent.
} 


\section{Fibrinogen}

Fibrinogen is a protein produced by the liver that circulates in the blood and helps stop bleeding by assisting blood clots to form. High fibrinogen has been identified as an important risk factor for cardiovascular disease. Fibrinogen and C-reactive protein levels appear to rise in response to stress stimuli and to take longer to return to normal levels among those in lower SES groups (Steptoe and Marmot, 2004). The normal range is $200-400 \mathrm{mg} / \mathrm{dl}$ (mg/dl = milligrams per deciliter) and above 400 is considered a high risk for heart disease.

Tables 7 and 8 also document US and English gradients in 'high' risk for men those ages 40-70.7 Once again, these can only be described as dramatically higher levels in the United States. The percent at high risk in the US is more than twice as large as it is in England, consistent with the much higher levels of heart disease in America obtained from self-reports. 21\% of American men have measured fibrinogen levels that place them at high risk—-the comparable rates in England are only 9\%.

Amongst all of our clinical measures, fibrinogen exhibits perhaps the sharpest SES gradients, a statement that would be equally true whether we used education or income to stratify the data. These social health gradients are much steeper in the United States than they are in the England. For example, compare American men in the lowest education group with those in the highest education group-32\% of those in the bottom are at 'high risk' compared to only $18 \%$ of those at the top. The comparable numbers in England are $12 \%$ and $7 \%$ respectively.

\section{Cholesterol}

Heart disease is caused by narrowing of the coronary arteries feeding the heart (arteriosclerosis). When the coronary arteries become narrowed by cholesterol and fat deposits and cannot supply enough blood to the heart, the result is coronary heart disease (CHD). When there is too much cholesterol in the bloodstream, some of the excess is deposited in the coronary arteries, where it contributes to the narrowing and blockages that can cause heart disease. LDL-C, the bad cholesterol, carries most of the cholesterol in the blood, and is the main source of damaging buildup and blockage in the arteries. NHANES and the HSE also contain measures of HDL-C (high density lipoproteins or the "good cholesterol” since high levels of HDL reduce risk for coronary heart disease by preventing plaques). We divide HDL cholesterol levels into three groups - more than or equal to $60 \mathrm{mg} / \mathrm{dL}$, which we describe as 'high,' 40-60mg/dl labeled 'normal,' and below 40 'low.' Levels in our high range have been established as reducing the risk of heart disease.

\footnotetext{
${ }^{7}$ In NHANES, fibrinogen tests done on performed on those 40 and over.
} 
Tables 7 and 8 present a parallel presentation for HDL cholesterol. Once again, there are large differences in this biological marker favoring the English over the Americans. Remembering that high HDL cholesterol is good for cardiovascular health, slightly less than one third of Americans in our age range of 55-64 have levels in this range. The comparable number in the HSE sample is 45\%. Almost three times as many Americans have low HDL readings compared to the English.

For income and especially for education, there are very sharp gradients in HDL-C levels in America compared to England. For example, among Americans between the ages of 40-70 who have less than a twelfth grade education, $12.5 \%$ have 'high' levels of HDL-C with an average reading of 45.3. In contrast, among Americans who have more than 12 years of schooling, 14.3\% have high HDL-C with a mean amount of 46.9. A similar if slightly muted gradient across income groups is also evident. When we combine and compare the education and income groups, those simultaneously in the highest education and income groups have more than twice the prevalence of HDL-C as those in the bottom end of both (35\% compared to 16\%). The social gradient in HDL levels is much more muted across either education or income in England.

\section{THE USE OF ABSOLUTE OR RELATIVE INCOME SCALES}

Using terciles of income in both countries, income gradients appear to be steeper in the US compared to England. Although we have largely followed convention for such international comparisons, we have been silent on the appropriate metric to adopt on the income scale. By using measures such as terciles, we have at least implicitly endorsed a relative income metric without really justifying it. The principal alternative is to compare social health gradients using absolute income levels in both countries. Although one can derive one from another with knowledge of the distribution of income, these comparative gradients will generally not be the same as one moves between an absolute and relative income metric.

For example, suppose that the two health-absolute income gradients are parallel and negatively sloped in the two countries, but that income dispersion is higher in the US than in England (as it is). Then health income gradients across percentiles, terciles, deciles, or quintiles or any type of relative income metric will necessarily steepen in the US compared to England when relative income metrics are used. Higher income dispersion in the US compared to England necessarily implies that, compared to slopes measured on an absolute income scale, there will be a greater increase in slope of the US health gradient (compared to the English one) when placed on the relative income scale.

Given this, the comparative nature of health gradients on alternative income scales cannot not tell us whether it is absolute or relative income that matters for health outcomes. Other tests are more appropriate to distinguish between them. For example if all that matters for health is relative income, then 
preserving dispersion, income growth should not matter for health. Similarly, if all that matters is absolute incomes, increasing dispersion at the top of the income distribution should not affect health outcomes of those at the bottom of the income hierarchy. These are the correct tests for deciding whether absolute or relative income matters and not a comparison of which of these two health gradients are steeper in the US compared to England.

In an international context, moving from relative income health gradients to absolute income gradients is more complicated then is generally recognized. There are several issues that have to be resolved. First, one must decide how to convert incomes measured in the currencies of one country into another. Purchasing Power Parity (PPP) is generally the preferred method since it is less subject to the vagaries of sharp financial fluctuations that can affect exchange rates. PPP estimates are available and debated vigorously but the conceptual and implementation problems here go beyond those thorny issues. In fact, it is these problems that make the use of relative scales so popular as all that matters are within country rankings into groups.

We can illustrate the difficulties with the steps necessary to convert incomes to the same absolute scale using ELSA and HRS. For openers, incomes are measured on a before tax basis in HRS but after tax in ELSA so it was necessary first to convert ELSA incomes to before tax and there is undoubtedly some imprecision in our conversion. But the issues go beyond taxes.

To illustrate, Table 9 gives a comparison of income levels and distributions in England and the US as recorded in ELSA and HRS for a sample of those 55-64 years old. To give an alternative benchmark in each country, data are also provided from the American Current Population Survey (CPS) and from the English Family Resources Survey (FRS). In this age group, using ELSA and HRS to measure reality, mean family incomes are 78\% higher in the US compared to England. These income differences expand noticeably across the income distribution—-for example $68 \%$ at the median and $95 \%$ at the $95^{\text {th }}$ percentile. Two contributing factors to this magnitude are that two low-income groups-African Americans and Latinos - have been excluded from the American sample, and income differences between the two countries reach their peak at in this age group. An overvalued American currency could also overstate the real differences, but even with those caveats in mind, the across country income difference seems large.

A significant part of this difference flows from the fact that family incomes in HRS are much higher than those reported in CPS for the same demographic subset of the population. For example, HRS mean family income is $17 \%$ higher than the CPS and the difference between these two US surveys expands as we move up the income distribution. The difference between these two surveys is $8 \%$ at the median and $26 \%$ at the $95^{\text {th }}$ percentile. Thus if CPS were compared to ELSA, the mean income difference 
between the two countries would be only 51\% instead of 78\%. Incomes in ELSA are about $4 \%$ lower than those obtained from FRS, so that a CPS-FRS yields a cross-country income differential of 45\%.

The question then is whether one should believe the HRS or CPS, which requires first an understanding of why their reports of family income could be so different. Table 10 separates out that component of mean family incomes in the two surveys that flow from income from capital, and within that sub-component the amount that is self-employment income and the amount that is the return on financial assets.

Income from capital essentially accounts for all the differences in mean income between the CPS and HRS. Within total capital income, three quarters of the difference between the two surveys appears in a single item—self-employment income, which on average are almost $\$ 9,000$ higher in HRS compared to CPS. This most likely stems from a difference in the questions asked. In CPS, respondents are asked a net income question of the form, "How much did (name/you) earn from (his/her/your) own business after expenses?” In contrast, the question asked in HRS is a gross income question of the form "about how much did your self-employment income amount to the last calendar year, including any profits left in the business, and before taxes and other deductions?” The form of the HRS question is unfortunate. Expenses are not income and this creates an unnecessary inconsistency between HRS income measurement and the other prominent American surveys that attempt to measure income.

Income from financial assets (largely dividends and interest) accounted for the rest of the difference the HRS and CPS. The issues involved in measuring these components of income were addressed in Hurd, Juster, and Smith (2003). A major innovation in HRS was a change in the way this type of income was measured. In its original waves, HRS measured capital income in a way very similar to that in CPS. When these household survey measures were compared to those in National Accounts, it was found that reporting in the household surveys was about half of the total from the National Accounts. The measurement innovation adopted by HRS was to integrate questions about capital income with questions about the existence and amount of wealth held in the assets that produced that income. This integration produced in HRS an across-wave increase of 63\% increase in the amount of income derived from financial assets, real estate investments and farm and business equity. As a result, capital income flows as measured in HRS were now much closer to those in the National Accounts.

It is likely then that some of the differences between CPS and HRS reflect better measurement in HRS and some reflects a poor question choice in HRS for the self-employment component. Since our main interest rests in the American-English comparison, we would also conclude that incomes as measured in HRS are to some degree artificially high relative to those in ELSA. It is difficult to establish precisely the magnitudes involved but HRS incomes could be as much as ten percent too high at the mean with an even larger discrepancy at the top tiers of the income distribution. 
These measurement issues can have important implications for how we interpret the income gradient in health across countries. Not only are income levels in the US higher on average in the HRS, but also American income as measured by the HRS is more dispersed than the CPS indicates. The implications for the social health gradient are two fold. At a given income level, health will be worse in the HRS compared to the CPS, and the health gradient will become less steep in the HRS compared to the CPS.

To illustrate the problems involved in comparing health gradients across countries, Figures $1 \mathrm{~A}$ and 2A plot for both countries the fraction of men in excellent or very good health (Figure 1A) and fair or poor health (Figure 2A) using income deciles in both England and the United States. From these graphs, we would conclude both that American men are healthier than Englishmen (which is we know is false and due only to the use of self-reported general health) and that income health gradients are steeper in the US compared to the England.

Figures 1B and 2B plot the same data but which each decile point indexed to an absolute income per week metric in both countries. Where one places these graphs for each country depends of course on the rate of conversion used between dollars and pounds (as well as on an assumption that this conversion rule does not vary by income position and certainly does not vary differentially by income position in the two countries). For these graphs, we used the 2002 exchange rate, which ex post may well represent an overvalued dollar. On each curve, data are marked by dark boxes (US) and lighter triangles (England).

The shape of the social gradient in health story now is quite different. Across most of the income distribution, the curves lie essentially on top of each other so that at each income male General Health Status (GHS) is the same in both countries and the gradients are equally negatively sloped. The principal difference between the two countries in Figures $1 \mathrm{~B}$ and 2B is that the US curve extends out much further to the right given the much higher concentration of income at the top in the US. Since those Americans within the extended part of the US curve are relatively healthy, translating the data in Figure 1B into Figure 1A produces a US curve that is above and steeper than the English health gradient.

Of course, we have argued that general health status is a treacherous health measure for international comparisons so we will rely now instead on some comparisons based on disease prevalence. Figures 3-5 compare the relative and absolute income gradients for three diseases-diabetes, heart diseases, and diseases of the lung- for which there appeared to be significant prevalence differences between the countries. Figure 3, which plots the prevalence of diabetes in the two countries, shows that whether relative or income scales are used, male diabetes prevalence is higher in the US compared to England. Across both absolute and relative income metrics, the differences between the two countries appear highest in the lower tiers of the income hierarchy but they never fully disappear even among the highest income groups. 
Figure 4 has a parallel set of plots for heart disease. Once again using either the relative or absolute income metric, at each income level heart disease is more common among American men compared to their English counterparts. Using either metric, there is a sharp negative gradient in heart disease as one moves from the bottom to the top of the income hierarchy in both countries - and these figures also indicate that this income gradient goes well beyond the terciles we presented in early sections, extending to the $10^{\text {th }}$ and $90^{\text {th }}$ percentiles of the income distribution. These steep income health gradients also characterize diseases of the lung which are plotted in Figures 5A and 5B - diseases of the

lung are almost seven times more likely among American men in the lowest income decile compared to those in the highest income decile. While not quite as steep, the income gradients are also steeply downward sloped across the income distribution in England.

\section{THE ROLE OF FEEDBACKS FROM HEALTH TO INCOME}

In the overall project of which this paper represents an early progress report, we plan to investigate several important factors that may account for the different shape of the social health gradient in these two countries. Among other things, these factors will include the nature and organization of work in England and the United States, the manner in which social and power structures are organized and the hierarchies that result from them, and the relative importance of feedback effects from health to SES in the two countries. In this paper, we present an initial examination of the possible differential feedbacks from health to income in England and the United States.

Studies based on the HRS have shown that, especially in the pre-retirement age groups considered, here there are significant feedbacks from health shocks to labor force exits and to lower household incomes (Smith 1999, 2005). The new availability of ELSA allows us to take an initial look at whether similar feedbacks exist in England. Given the greater governmental support system in England compared to the US, we anticipate that labor force exits due to health shocks might even be larger in England than in the United States, but that the income losses associated with these exits might be smaller.

Tables 11A and B (for England) and 12A and B (for the US) provide an initial look at this issue by breaking down the income patterns we saw earlier into finer age groups across which labor market participation will differ. The left hand panels show the fraction of those in poor or fair health at each age specific income quartile. Especially for those in their early fifties, a large fraction of those in the bottom income quartile self-report report themselves in poor health in both countries. For example, among those who are ages 54-57 one third of those in the bottom income quartile self-report their health as poor or fair in England-the corresponding fraction in the Unites States is 42 percent.

In both countries, these fractions in poor health decline significantly as one moves up the income quartiles. In this age group, the fraction in poor or fair health is only one in every four in the second to the 
bottom income quartile and is about twelve percent in the highest income quartile. An even more sharply declining fraction in poor health exists in the United States where the percent in poor health in the highest income quartile is about seven percent among men of this age group.

These patterns by themselves are simply another way of expressing the social health gradient along the income divide and tell us nothing about the underlying mechanisms at work. The right hand panels in these tables provide a step in that direction. These panels document for the same income quartiles the fraction in each quartile who are not working. A large fraction of those in the bottom income quartile again in both countries are not working even for those ages 54-57. In England, 41 percent of those in the bottom income quartile are not working compared to seven percent who are not working in the highest income quartile. In this age group at least, the numbers who are not working are almost identical in the United States.

We have established then that in both England and the United States that non-work and poor health are important attributes of those at the lower end of the income distribution and that work and good health characterize those at the top of the income distribution. But is there a reason to believe that nonwork and poor health are related?

Tables 11B and 12B complete the thought by showing that a very large fraction of those who are not working in the lowest income quartile in both countries self-report themselves in poor health. In England, 85 percent of those in poor health are not working- in the United States the corresponding fraction is 70 percent. Poor health is more closely related to non-work in England than in the United States, lending some support to our first conjecture above that at least in these age groups that poor health is more likely to lead to labor force exit in England than in the United States.

These patterns in both countries are suggestive that there may well be important feedbacks from health to labor force exits to low incomes. While the strength of these pathways from health to income during the pre-retirement years has been established in the United States (Smith 1999, 2005), very little is currently known about them in England. ELSA now provides the opportunity for such a test. Even though our analysis does not use wave 2 data, ELSA is derived from a sample of individuals who had previously participated in the Health Survey for England (HSE) and there exists sufficient information about their labor force activity and incomes to estimate the impact of a new health event on both labor force activity and income.

Our tests for England of the pathway from health shocks to labor force exits and any reductions in income that may accompany these exits are provided in Tables 13 and 14. In Table 13, we estimate the probability of a labor force exit for ELSA respondents between the time they participated in the 1998 Health Survey for England (HSE) and the ELSA baseline interview. The 1998 HSE specialized in heart disease so that we can monitor the impacts of new illnesses of this type between these waves. In addition 
to controls for education, age, gender, marital status, and whether a person hit the state pension ages between 1998 and 2002, we also control for baseline health in the form of self-reported health status. Two measures of new health events or health shocks are used, both involving the onset of an illness between the 1998 HSE and the baseline ELSA waves. The first represents the onset of a serious health shockheart attacks and strokes—while the second includes less serious health onsets (diabetes, HBP, and angina).

Two equations are estimated. The first is a probit for the probability of a labor force exit between these two waves (Table 13). The results obtained for the variables other than the new health events are as expected. The probability of a labor force exit declines with education, is lower for men than women, and increases in age. The probability of an exit is also higher is an individual becomes age eligible for a state pension between the two waves.

There are two types of health variables in this model. The first measures self-reported general health status at baseline and labor force exits decrease as baseline health improves. Since the outcome conditions on working at baseline, this may suggest that new health events (not captured by our two measures) are more likely for the less healthy at baseline. Finally, there are two measures of new health events that are included in our model. For these variables, our estimates mimic findings from the HRS (see Smith (2005)). In particular, serious health onsets (the onset of a heart attack or stroke) are strong predictors of labor market exits while the onsets of more minor conditions have a much more reduced impact on work.

The second model is the percent family income change between the two waves (Table 14). Our estimates indicate that a serious health onset reduces family income by $19 \%$ while not surprisingly given the small labor market effects the impact of minor onsets is quite small. The second model listed in Table 14 adds a control that indicates that the respondent reaches the state pension age between the waves. Reaching the state pension is associated with a reduction in family incomes of 17 percent if the individual stops working indicating that there is not full income replacement associated with retirement. This implied replacement rate is quite similar to those computed in Banks, Blundell and Smith (2003).

The estimates in the second model also indicate that family income reductions due to severe health shocks also result in family income declines of about 17 percent, very similar to those incurred for those who stop work due to reaching the state pension age. This suggests that overall income replacement rates are roughly similar no matter what the reason for labor market exit.

These results represent at best an initial stab at these important issues. They do suggest that feedbacks from health to labor force activity and to income are an important part of the SES health income gradient in England as well as the United States. Further analysis using the second wave of ELSA 
will be better able to provide more definitive tests of the differences as well as similarities that exist across countries.

\section{WEALTH AS AN ALTERNATIVE MARKER FOR THE SOCIAL GRADIENT IN HEALTH}

The simultaneous availability of alternative measures of financial resources beyond the traditional use of household income has sparked interest both in how these new measures impact on health and how they may also be affected by health. The most important of these new measures involves the financial wealth held by individuals and families. Even among families with the same amount of income, there is a substantial variation in the amount of financial wealth they possess. There are also large differences in financial wealth holdings between England and the United States (Banks, Blundell, and Smith, 2003). Among those between ages 40 and 60 for example, Banks, Blundell, and Smith report that mean financial assets are more than twice as large in American households compared to English households although some of these differences are offset by higher housing wealth in Britain. These differences become much bigger at the top of the financial wealth distributions. At the $90^{\text {th }}$ percentile American households held $\$ 172,000$ in financial assets compared to only $\$ 62,000$ among English households. Financial wealth is far more unequally distributed than is family income and this is much truer in America than in England.

The independent effects of wealth on health status over and above any impact income may have is a largely unexplored topic of research although accumulated wealth - in particular the indication it gives of permanent income levels and the security it provides over and above current income - could well link differently with health outcomes. In recent papers, Smith $(1999,2004)$ reported that neither financial assets nor family income predicted the new onset of disease among American middle age adults. On the other hand, Smith estimated relatively large effects of new health events on the wealth holdings of mature American households. Whether or not these results applied to England is very much an open question, the resolution of which must await analysis on multiple waves of the ELSA panel.

We rely here only on cross-sectional comparisons of social health gradients in the 2002 HRS and ELSA data using net financial wealth as the alternative SES marker. Table 15 lists prevalence rates of the same diseases listed in Table 1, but now these prevalences are arrayed by quintiles of financial wealth instead of income.

Negative health gradients also exist in both countries across financial wealth quintiles and once again the differences between the two countries in the overall levels of disease is enough to dominate the comparisons across wealth groups. For example, even though Americans in the highest quintile of net financial wealth have far more assets than English men do in any of their wealth quintiles, rates of diabetes are higher in the US - American men in the highest wealth quintile have a minimum of \$146,900 in net financial assets while English men in the lowest wealth quintile have less than $\$ 800$. But rates or 
diabetes are these two groups are about the same. Financial resources alone are clearly not sufficient to prevent diabetes.

Relatively speaking, however, the steepness of the gradients in health across the net financial wealth distribution is not so strikingly different across countries than in the income case. Indeed, if anything, the gradients in terms of relative risks are a little steeper in the UK than in the US when we rank individuals by net financial wealth.

We do not pursue the same detailed comparisons of relative and 'absolute' gradients by wealth that we did for income in Figures 5.1 to 5.5. Nevertheless some idea of the effects of such an adjustment can be obtained from looking at the cut points for the wealth quintiles in each country, presented in Table 15. The increased wealth inequality in the US is immediately apparent, with the $20^{\text {th }}$ percentile of the distribution being $62.5 \%$ of the corresponding value in England ( $\$ 500$ instead of $\$ 800)$ and the $80^{\text {th }}$ percentile being $130 \%$ of the English value (\$146,900 as opposed to $\$ 112,700$ ). Forgetting the difference in the levels for a minute and concentrating on relative risks, since the health gradients by wealth quintile are equally steep in each country the adjustment to a gradient measured across absolute levels of wealth will tend to make the gradient in the US flatter than that observed in England over a common wealth range.

Clearly this is a potentially interesting avenue for future research. One question is simply the degree of trans-Atlantic variation in the extent to which individuals are ranked differently in the income and wealth distributions, which will presumably depend on the different institutional arrangements for income maintenance in the two countries and how each might depend on the level of financial wealth the household may have. A second question is the extent to which income and wealth correlate differently with risk factors and health behaviors in the two countries, and particularly those that may have occurred in early life. The final issue is then to relate any such differences to differences in health outcomes or factors (such as stress, status or control, for example) that are linked with such health outcomes.

\section{CONCLUSIONS}

In this paper, we have presented data on some of the most salient issues regarding the social health gradient in health and the manner in which this health gradient differs for men in England and the United States. There are a several key findings. First, looking across a wide variety of diseases, average health status among mature men is much worse in America compared to England, confirming non-gender specific findings we reported in Banks, Marmot, Oldfield, and Smith, 2006. Second, there exists a steep negative health gradient for men in both countries where men at the bottom of the economic hierarchy are in much worse health than those at the top. This social health gradient exists whether education, income, or financial wealth is used as the marker of one's SES status. While the negative social gradient in male 
health characterizes men in both countries, it appears to be steeper in the United States. These central conclusions are maintained even after controlling for a standard set of behavioral risk factors such as smoking, drinking, and obesity and are equally true using either biological measures of disease or individual self-reports.

In contrast to these disease based measures of health, health of American men appears to be superior to the health of English men when self-reported general health status is used as the measure of health status. This apparent contradiction does not result from differences in co-morbidity, emotional health, or ability to function all of which still point to mature American men being less healthy than their English counterparts. The contradiction most likely stems instead from different thresholds used by Americans and English when evaluation their health status on subjective scales. For the same 'objective' health status, Americans are much more likely to say that their health is good than are the English.

Finally, we present preliminary data that indicates that feedbacks from new health events to household income are also one of the reasons that underlie the strength of the income gradient with health in England. Previous research has demonstrated its importance as one of the underlying causes in the United States and these results suggest that that conclusion should most likely be extended to England as well. 


\section{References}

Adams, Peter, Michael Hurd, Daniel McFadden, Angela Merrill, and Tiago Ribeiro. 2003. "Healthy, Wealthy, and Wise? Tests for Direct Causal Paths Between Health and Socioeconomic Status," Journal of Econometrics 112:3-56.

Banks, James, Richard Blundell, and James P. Smith. 2003. "Understanding Differences in Household Financial Wealth between the United States and Great Britain,” Journal of Human Resources 38(2):241-279.

Banks, James, Michael Marmot, Zoe Oldfield, and James P. Smith. "Disease and Disadvantage in the USA and in England,” JAMA, forthcoming April 2006.

Goodman, Noreen, I-Fen Lin, Maxine Weinstein, and Yu-Hsuan Lin. 2003. "Evaluating the Quality of Self-Reports of Hypertension and Diabetes,” Journal of Clinical Epidemiology 56:148-154.

Harris M.I., K. M. Flegal, C. C. Cowie, M. S. Eberhardt, D. E. Goldstein, R. R. Little, H. M. Wiedmeyer, and D. D. Byrd-Holt. 1998. "Prevalence of Diabetes, Impaired Fasting Glucose, and Impaired Glucose Tolerance in U.S. Adults,” The Third National Health and Nutrition Examination Survey, 1988-1994. Diabetes Care 21:518-524.

Health Survey for England. 2003. Methodology and Documentation, Series HS Number 13.

Hurd, Michael, F. Thomas Juster, and James P. Smith. 2003. "Enhancing the Quality of Data on Income: Recent Innovations from the HRS,” Journal of Human Resources 38(3):758-772.

Kapteyn, Arie, James P. Smith, and Arthur van Soest. 2004. “ Self-Reported Work Disability in the US and The Netherlands,” October 2004.

Marmot, Michael. 1999. “A Multi-Level Approaches to Understanding Social Determinants,” in Lisa Berkman and Ichiro Kawachi (eds.), Social Epidemiology, Oxford University Press, Oxford.

Marmot, Michael, James Banks, Richard Blundell, Carli Lessof, and James Nazroo. 2003. "Health, Wealth, and Lifestyles of the Older Population in England-The 2002 English Longitudinal Study of Ageing,” Institute of Fiscal Studies, December 2003.

Melia J, Moss S, Johns L. 2004. "Rates of prostate-specific antigen testing in general practice in England and Wales in asymptomatic and symptomatic patients: a cross-sectional study,” BJU.Int. 94:51-6.

Mendall, M.A., P. Patel, and L. Ballam et al. 1996. "C-reactive Protein and its Relation to Cardiovascular Risk Factor,” BMJ, 312:1061-1065.

National Institutes on Health: National Heart, Lung, and Blood Institute. 1997. Sixth Report of the Joint National Committee on the Prevention, Detection, Evaluation and Treatment of High Blood Pressure, NIH Publication No. 98-04080.

Salomon, J., A. Tandon, and C. Murray. 2004. "Comparability of Self rated Health: Cross Sectional Multi-country Survey Using Anchoring Vignettes,” British Medical Journal 328(7434):258-260. 
Sirovich B.E., L.M. Schwartz, and S. Woloshin. 2003. "Screening men for prostate and colorectal cancer in the United States: does practice reflect the evidence?” JAMA 289:1414-20

Smith, James P. 1999. "Healthy Bodies and Thick Wallets," Journal of Economic Perspectives 13(2):108-132.

Smith, James P. 2004. "Unraveling the SES Health Connection,” Population and Development Review. Aging, Health, and Public Policy: Demographic and Economic Perspectives 30:133-150.

Steptoe, Andrew, and Michael Marmot. 2004. "Socioeconomic Status and Coronary Heart Disease: A Psychobiological Perspective,” Population and Development Review. Aging, Health, and Public Policy: Demographic and Economic Perspectives 30:133-150.

Wilkinson, Richard G. 1996. Unhealthy Societies: The Afflictions of Inequality. London, Routledge. 
Table 1

Health Outcomes By SES in England and the United States

(Men ages 55-64 years old)

Diabetes

\begin{tabular}{cccccrrrr}
\hline & & \multicolumn{3}{c}{ England } & \multicolumn{2}{c}{ U.S. } \\
$\begin{array}{c}\text { Income } \\
\text { Tercile }\end{array}$ & Low & Medium & High & Total & Low & Medium & High & Total \\
\hline 1 & 9.0 & 5.4 & 8.5 & 8.1 & 23.2 & 15.8 & 15.2 & 20.4 \\
2 & 9.2 & 7.1 & 6.7 & 7.9 & 14.1 & 15.2 & 15.7 & 14.8 \\
3 & 5.4 & 3.9 & 6.4 & 5.5 & 8.1 & 6.8 & 11.0 & 9.5 \\
Total & 8.3 & 5.5 & 6.8 & 7.1 & 16.6 & 12.6 & 12.7 & 14.4 \\
& & & & & & & &
\end{tabular}

Hypertension

\begin{tabular}{ccccccccc}
\hline & \multicolumn{4}{c}{ England } & \multicolumn{3}{c}{ Uears of Schooling } \\
$\begin{array}{c}\text { Income } \\
\text { Tercile }\end{array}$ & Low & Medium & High & Total & Low & Medium & High & Total \\
\hline 1 & 42.8 & 30.7 & 29.2 & 37.5 & 54.5 & 50.5 & 40.9 & 51.6 \\
2 & 35.1 & 36.1 & 34.9 & 35.3 & 51.3 & 48.6 & 42.4 & 48.5 \\
3 & 33.0 & 27.2 & 31.9 & 30.9 & 41.9 & 40.9 & 41.6 & 41.5 \\
Total & 37.9 & 31.3 & 32.2 & 34.4 & 50.8 & 46.6 & 41.7 & 46.8 \\
\hline
\end{tabular}

All Heart Disease

\begin{tabular}{|c|c|c|c|c|c|c|c|c|}
\hline \multirow{3}{*}{$\begin{array}{l}\text { Income } \\
\text { Tercile }\end{array}$} & \multicolumn{5}{|c|}{ England } & \multicolumn{2}{|c|}{ U.S. } & \multirow[b]{3}{*}{ Total } \\
\hline & \multicolumn{5}{|c|}{ Years of Schooling } & \multirow{2}{*}{\multicolumn{2}{|c|}{ Medium }} & \\
\hline & Low & Medium & High & Total & Low & & & \\
\hline 1 & 21.4 & 15.6 & 11.5 & 18.2 & 26.7 & 25.8 & 17.8 & 25.2 \\
\hline 2 & 12.5 & 8.9 & 10.4 & 11.0 & 14.8 & 19.1 & 15.3 & 16.0 \\
\hline 3 & 9.5 & 10.3 & 8.7 & 9.3 & 12.8 & 13.8 & 14.8 & 14.1 \\
\hline Total & 15.6 & 11.2 & 9.7 & 12.6 & 19.2 & 19.3 & 15.3 & 17.9 \\
\hline \multicolumn{9}{|c|}{ Heart Attack } \\
\hline & \multicolumn{4}{|c|}{ England } & & \multirow{2}{*}{\multicolumn{2}{|c|}{ U.S. }} & \\
\hline Income & \multicolumn{6}{|c|}{ Years of Schooling } & & \\
\hline Tercile & Low & Medium & High & Total & Low & Medium & High & Total \\
\hline 1 & 11.6 & 10.2 & 7.9 & 10.6 & 16.4 & 10.7 & 10.4 & 14.3 \\
\hline 2 & 5.2 & 4.7 & 3.2 & 4.6 & 5.1 & 7.8 & 8.5 & 6.6 \\
\hline 3 & 2.3 & 5.5 & 4.7 & 4.3 & 5.6 & 2.3 & 4.9 & 4.6 \\
\hline Total & 7.3 & 6.4 & 4.9 & 6.3 & 9.7 & 6.8 & 6.5 & 8.0 \\
\hline \multicolumn{9}{|c|}{ Stroke } \\
\hline & \multicolumn{5}{|c|}{ England } & \multirow{2}{*}{\multicolumn{2}{|c|}{ U.S. }} & \\
\hline Income & & & & Yea & poling & & & \\
\hline Tercile & Low & Medium & High & Total & Low & Medium & High & Total \\
\hline 1 & 5.3 & 3.3 & 2.0 & 4.2 & 7.0 & 4.7 & 3.7 & 6.0 \\
\hline 2 & 2.1 & 3.0 & 3.0 & 2.6 & 5.3 & 4.8 & 5.0 & 5.1 \\
\hline 3 & 2.6 & 3.6 & 1.3 & 2.2 & 3.8 & 0.9 & 0.8 & 1.5 \\
\hline Total & 3.5 & 3.2 & 1.9 & 3.0 & 5.7 & 3.5 & 2.2 & 4.0 \\
\hline
\end{tabular}


Lung Disease

\begin{tabular}{|c|c|c|c|c|c|c|c|c|}
\hline \multirow{3}{*}{$\begin{array}{l}\text { Income } \\
\text { Tercile }\end{array}$} & \multicolumn{5}{|c|}{ England } & \multicolumn{3}{|c|}{ U.S. } \\
\hline & & & & \multicolumn{2}{|c|}{ Years of Schooling } & \multirow{2}{*}{\multicolumn{2}{|c|}{ Medium High }} & \multirow[b]{2}{*}{ Total } \\
\hline & Low & Medium & High & Total & Low & & & \\
\hline 1 & 10.4 & 6.5 & 4.9 & 8.5 & 12.6 & 8.7 & 5.2 & 10.6 \\
\hline 2 & 8.3 & 4.9 & 4.0 & 6.2 & 8.5 & 9.4 & 2.9 & 7.4 \\
\hline 3 & 5.0 & 3.4 & 2.1 & 3.2 & 5.2 & 4.5 & 2.3 & 3.4 \\
\hline Total & 8.4 & 4.7 & 3.1 & 5.8 & 9.5 & 7.6 & 2.8 & 6.8 \\
\hline \multicolumn{9}{|c|}{ Cancer } \\
\hline & \multirow{2}{*}{\multicolumn{5}{|c|}{ Years of Schooling }} & \multirow{2}{*}{\multicolumn{2}{|c|}{ U.S. }} & \\
\hline Income & & & & & & & & \\
\hline Tercile & Low & Medium & High & Total & Low & Medium & High & Total \\
\hline 1 & 4.7 & 2.9 & 6.9 & 4.7 & 7.2 & 5.5 & 9.7 & 7.2 \\
\hline 2 & 5.1 & 5.5 & 1.2 & 4.2 & 6.0 & 8.8 & 4.8 & 6.4 \\
\hline 3 & 1.3 & 0.6 & 3.4 & 2.1 & 5.9 & 10.1 & 8.4 & 8.2 \\
\hline Total & 4.1 & 3.0 & 3.5 & 3.6 & 6.5 & 8.3 & 7.7 & 7.3 \\
\hline
\end{tabular}

Sources: English data is from first wave of ELSA. American data is from the 2002 wave of the HRS. 
Table 2

Reports of General Health Status in England and the United States

(Men ages 55-64 years old)

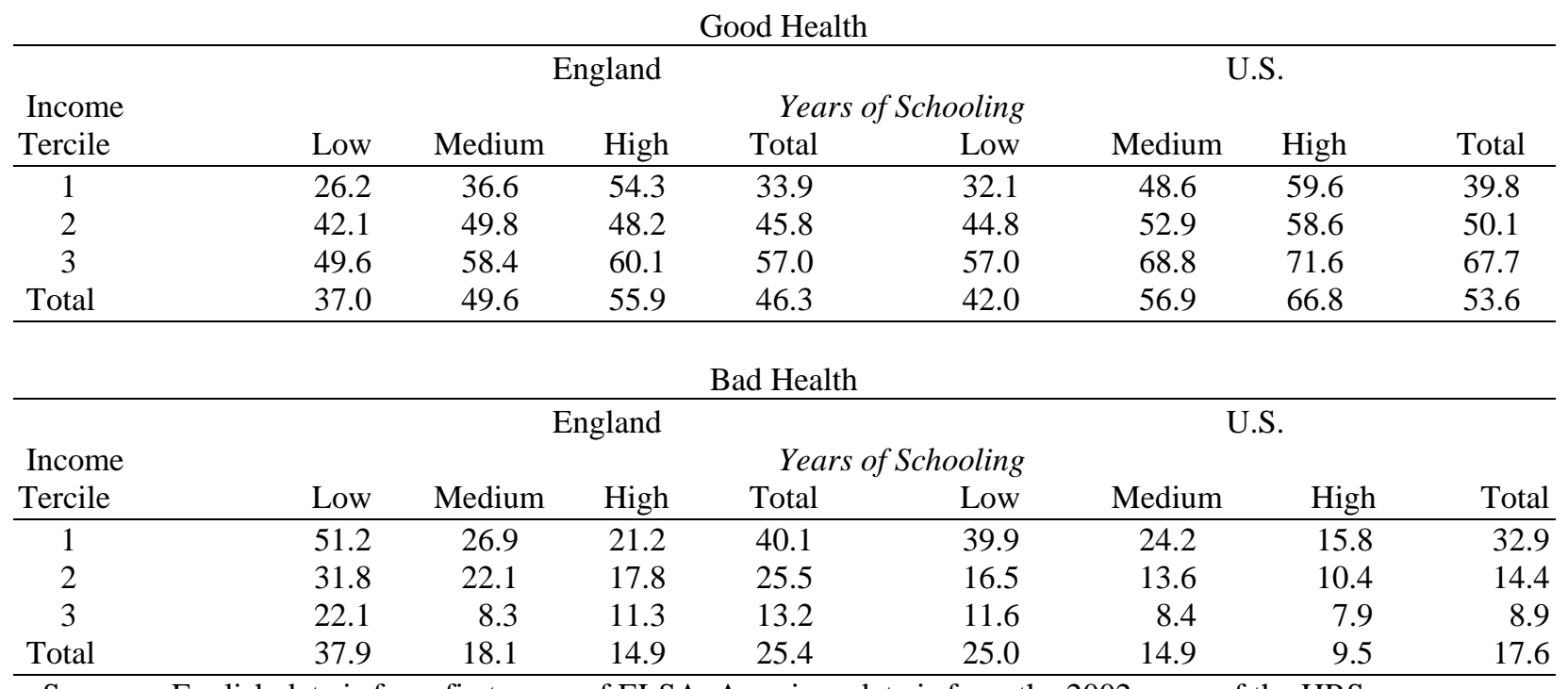

Sources: English data is from first wave of ELSA. American data is from the 2002 wave of the HRS. 
Table 3

Health Status in England and the United States

(Men ages 55-64 years old)

Emotional Problems

\begin{tabular}{cccccccrrr}
\hline & \multicolumn{3}{c}{ England } & \multicolumn{3}{c}{ U.S. } \\
$\begin{array}{c}\text { Income } \\
\text { Tercile }\end{array}$ & Low & Medium & High & Total of Schooling & Low & Medium & High & Total \\
\hline 1 & 10.4 & 10.4 & 5.1 & 9.4 & 18.2 & 19.4 & 22.4 & 19.1 \\
2 & 3.8 & 6.0 & 7.1 & 5.3 & 8.3 & 12.1 & 5.7 & 8.6 \\
3 & 5.8 & 4.0 & 6.1 & 5.4 & 6.6 & 8.5 & 11.4 & 9.7 \\
Total & 7.0 & 6.4 & 6.2 & 6.6 & 12.0 & 12.9 & 11.3 & 12.0 \\
\hline
\end{tabular}

Co-morbidity (\% with two or more conditions given you have at least one)

\begin{tabular}{ccccccccr}
\hline & \multicolumn{3}{c}{ England } & \multicolumn{3}{c}{ Years of Schooling } & \multicolumn{3}{c}{ U.S. } \\
Income & Low & Medium & High & Total & Low & Medium & High & Total \\
\hline 1 & 41.7 & 36.2 & 32.4 & 39.2 & 56.2 & 45.6 & 40.7 & 52.0 \\
2 & 34.8 & 24.1 & 31.5 & 30.9 & 45.3 & 43.4 & 41.4 & 44.0 \\
3 & 15.6 & 32.5 & 29.9 & 26.4 & 25.9 & 34.2 & 37.1 & 33.9 \\
Total & 34.4 & 30.1 & 30.8 & 32.4 & 46.9 & 41.6 & 38.7 & 43.2 \\
\hline
\end{tabular}

$\%$ with one or more mobility limitations

\begin{tabular}{|c|c|c|c|c|c|c|c|c|}
\hline \multirow{3}{*}{$\begin{array}{l}\text { Income } \\
\text { Tercile }\end{array}$} & \multicolumn{5}{|c|}{ England } & \multicolumn{2}{|c|}{ U.S. } & \multirow[b]{3}{*}{ Total } \\
\hline & \multirow[b]{2}{*}{ Low } & \multirow[b]{2}{*}{ Medium } & \multirow[b]{2}{*}{ High } & \multicolumn{2}{|c|}{ Years of Schooling } & \multirow[b]{2}{*}{ Medium } & \multirow[b]{2}{*}{ High } & \\
\hline & & & & Total & Low & & & \\
\hline 1 & 58.3 & 45.9 & 38.4 & 51.7 & 67.0 & 56.2 & $\begin{array}{l}0 \\
40.7\end{array}$ & 60.8 \\
\hline 2 & 45.0 & 42.2 & 34.1 & 41.4 & 51.0 & 51.2 & 33.3 & 46.8 \\
\hline 3 & 36.3 & 21.1 & 25.2 & 26.9 & 41.5 & 51.2 & 33.6 & 38.8 \\
\hline Total & 48.7 & 35.2 & 30.0 & 39.2 & 55.6 & 52.6 & 34.4 & 47.8 \\
\hline
\end{tabular}

Sources: English data is from first wave of ELSA. American data is from the 2002 wave of the HRS. 
Table 4

Male Risk Factors By SES in England and the United States

(Ages 55-64 years old)

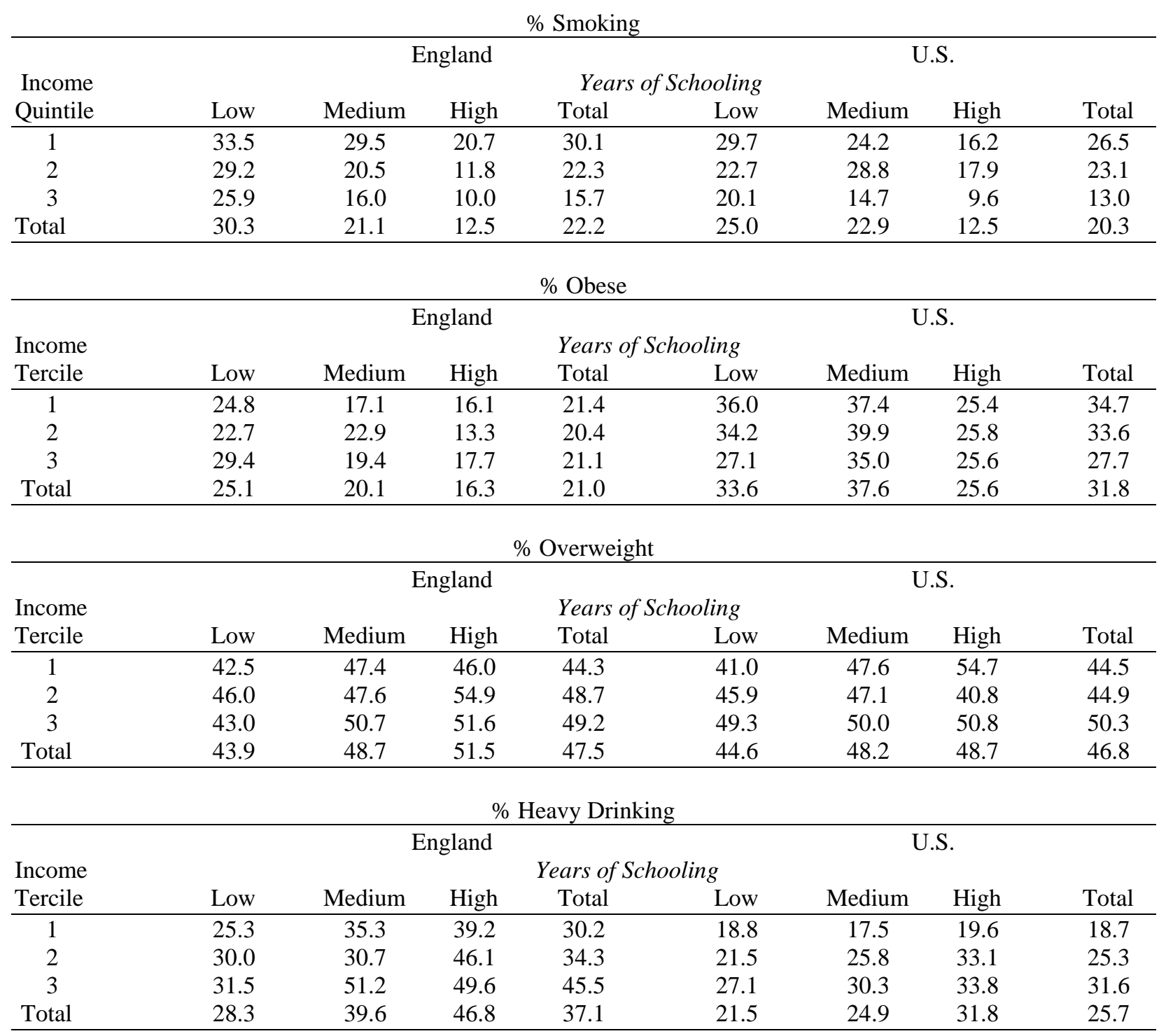

Sources: English data is from first wave of ELSA. American data is from the 2002 wave of the HRS.

Notes: Obesity is defined as BMI $>30$, Overweight is defined as BMI between 25 and 30; Heavy drinking is defined as drinking on more than 4 days per week in HRS and twice a day or more/daily or almost daily in ELSA 
Table 5A

Relation between Self and Biological Reports for Diabetes (Men ages 55-64 years old)

\begin{tabular}{lcccccc}
\hline & \multicolumn{3}{c}{ United States } & \multicolumn{3}{c}{ England } \\
Biological Report & \multicolumn{2}{c}{ Self Report } & Row \% & Self Report & Row \% \\
\hline & No & Yes & & No & Yes \\
No & 87.0 & 2.1 & 89.1 & 91.4 & 1.8 & 93.2 \\
Yes & 2.5 & 8.4 & 10.9 & 2.3 & 4.5 & 6.8 \\
Column \% & 89.5 & 10.5 & & 93.7 & 6.3 & \\
\hline
\end{tabular}

Source: United States: NHANES 1999-2002—uses 6.5\% cutoff on HbA1c. England: HSE 2003uses $6.5 \%$ cutoff on HbA1c.

Table 5B

Comparison of Self and Biological Reports for Diabetes by SES

(Men ages 40-70 years old)

\begin{tabular}{lcccccc}
\hline & $\begin{array}{c}\text { Self } \\
\text { Reports }\end{array}$ & $\begin{array}{c}\text { United States } \\
\text { Biological } \\
\text { Reports }\end{array}$ & $\begin{array}{c}\% \\
\text { Undiagnosed }\end{array}$ & $\begin{array}{c}\text { Self } \\
\text { Reports }\end{array}$ & $\begin{array}{c}\text { England } \\
\text { Biological } \\
\text { Reports }\end{array}$ & $\begin{array}{c}\% \\
\text { Undiagnosed }\end{array}$ \\
\hline Education & & & & & & \\
$\quad$ Low & 13.5 & 16.7 & 30.9 & 5.5 & 6.8 & 35.4 \\
$\quad$ Middle & 8.9 & 9.8 & 25.4 & 3.6 & 4.1 & 34.4 \\
$\quad$ High & 7.4 & 6.8 & 18.8 & 4.2 & 4.1 & 20.2 \\
Income & & & & & & \\
$\quad$ Low & 12.7 & 14.7 & 28.2 & 7.5 & 6.8 & 25.1 \\
$\quad$ Middle & 7.7 & 6.7 & 18.8 & 2.8 & 2.9 & 34.3 \\
$\quad$ High & 5.2 & 5.1 & 15.6 & 3.2 & 4.5 & 31.3 \\
All & 8.6 & 8.9 & 23.3 & 4.4 & 4.8 & 29.3 \\
\hline
\end{tabular}

Source: United States: NHANES 1999-2002-uses 6.5\% cutoff on HbA1c. England: HSE 2003uses $6.5 \%$ cutoff on HbA1c.

Table 5C

Relation between Self and Biological Reports for Diabetes

(Men ages 55-64 years old)

\begin{tabular}{|c|c|c|c|c|c|c|}
\hline \multirow{3}{*}{ Biological Report } & \multicolumn{3}{|c|}{ United States } & \multicolumn{3}{|c|}{ England } \\
\hline & \multicolumn{2}{|c|}{ Self Report } & \multirow[t]{2}{*}{ Row \% } & \multicolumn{2}{|c|}{ Self Report } & \multirow[t]{2}{*}{ Row \% } \\
\hline & No & $\mathrm{Ye}$ & & No & Yes & \\
\hline No & 87.8 & 5.1 & 92.9 & 92.9 & 2.5 & 95.3 \\
\hline Yes & 1.5 & 5.6 & 7.1 & 0.8 & 3.9 & 4.7 \\
\hline Column \% & 89.2 & 10.8 & & 93.7 & 6.3 & \\
\hline
\end{tabular}


Table 6A

Relation between Self and Biological Reports for High Blood Pressure (Men ages 55-64 years old)

\begin{tabular}{lcccccc}
\hline & \multicolumn{3}{c}{ United States } & \multicolumn{3}{c}{ England } \\
Biological Report & \multicolumn{2}{c}{ Self Report } & Row \% & \multicolumn{2}{c}{ Self Report } & Row \% \\
\hline & No & Yes & & No & Yes \\
No & 52.4 & 4.7 & 57.1 & 41.9 & 15.8 & 57.8 \\
Yes & 9.8 & 33.1 & 42.9 & 18.8 & 23.5 & 42.2 \\
Column \% & 62.2 & 37.8 & & 60.7 & 39.3 & \\
\hline
\end{tabular}

Source: United States: NHANES 1999-2002. England: HSE 2003.

Table 6B

Comparison of Self and Biological Reports for Hypertension by SES

(Men ages 40-70 years old)

\begin{tabular}{lcccccc}
\hline & $\begin{array}{c}\text { Self } \\
\text { Reports }\end{array}$ & $\begin{array}{c}\text { United States } \\
\text { Biological } \\
\text { Reports }\end{array}$ & $\begin{array}{c}\% \\
\text { Undiagnosed }\end{array}$ & $\begin{array}{c}\text { Self } \\
\text { Reports }\end{array}$ & $\begin{array}{c}\text { England } \\
\text { Biological } \\
\text { Reports }\end{array}$ & $\begin{array}{c}\% \\
\text { Undiagnosed }\end{array}$ \\
\hline $\begin{array}{c}\text { Education } \\
\text { Low }\end{array}$ & 37.8 & 38.7 & 17.1 & 36.6 & 41.1 & 36.4 \\
$\quad$ Middle & 31.0 & 35.6 & 24.9 & 33.1 & 36.3 & 36.3 \\
$\quad$ High & 26.9 & 31.2 & 26.3 & 28.7 & 32.8 & 37.3 \\
$\begin{array}{l}\text { Income } \\
\text { Low }\end{array}$ & 34.0 & 37.8 & 22.2 & 42.7 & 40.0 & 27.6 \\
$\quad$ Middle & 25.0 & 29.7 & 28.9 & 28.8 & 34.9 & 40.0 \\
$\quad$ High & 28.7 & 32.0 & 23.5 & 27.9 & 32.0 & 38.4 \\
All & 29.3 & 33.2 & 24.6 & 32.0 & 36.0 & 36.7 \\
\hline
\end{tabular}

Source: United States: NHANES 1999-2002. England: HSE 2003. 
Table 7. Comparison of Male Self and Biological Reports by SES (ages 40-70 years old), by Education

\begin{tabular}{|c|c|c|c|c|c|c|c|c|}
\hline & \multicolumn{4}{|c|}{ England } & \multicolumn{4}{|c|}{ United States } \\
\hline & Low & Medium & High & All & Low & Medium & High & All \\
\hline \multicolumn{9}{|l|}{ Diabetes } \\
\hline \% prevalence (Self Reports) & 5.5 & 3.6 & 4.2 & 4.4 & 13.5 & 8.9 & 7.4 & 8.6 \\
\hline \% prevalence (Biological Reports ${ }^{(1)}$ ) & 6.8 & 4.1 & 4.1 & 4.8 & 16.7 & 9.8 & 6.8 & 8.9 \\
\hline \multicolumn{9}{|l|}{ Hypertension } \\
\hline \% prevalence (Self Reports) & 36.6 & 33.1 & 28.7 & 32.0 & 37.8 & 31.0 & 26.9 & 29.3 \\
\hline \% prevalence (Biological Reports ${ }^{(2)}$ ) & 41.1 & 36.3 & 32.8 & 36.0 & 38.7 & 35.6 & 31.2 & 33.2 \\
\hline \multicolumn{9}{|l|}{ C-reactive Protein } \\
\hline \% High Risk ${ }^{(3)}$ & 36.2 & 28.3 & 22.7 & 27.7 & 47.1 & 35.2 & 28.4 & 32.5 \\
\hline \% Moderate Risk ${ }^{(4)}$ & 40.2 & 42.5 & 38.1 & 39.9 & 34.5 & 39.7 & 37.6 & 37.7 \\
\hline \% Low Risk ${ }^{(5)}$ & 23.6 & 29.2 & 39.2 & 32.3 & 18.4 & 25.1 & 34.1 & 29.9 \\
\hline Mean (mg/dL) & 0.41 & 0.34 & 0.29 & 0.33 & 0.51 & 0.38 & 0.31 & 0.36 \\
\hline Median (mg/dL) & 0.20 & 0.17 & 0.13 & 0.16 & 0.28 & 0.20 & 0.15 & 0.18 \\
\hline \multicolumn{9}{|l|}{ Fibrinogen } \\
\hline \% High Risk ${ }^{(6)}$ & 11.9 & 8.8 & 7.3 & 8.8 & 31.8 & 24.5 & 17.6 & 21.2 \\
\hline Mean (mg/dL) & 309 & 302 & 287 & 296 & 377 & 355 & 342 & 350 \\
\hline Median (mg/dL) & 300 & 290 & 280 & 290 & 367 & 347 & 333 & 342 \\
\hline \multicolumn{9}{|l|}{ HDL Cholesterol } \\
\hline \% High ${ }^{(7)}$ & 22.3 & 25.9 & 30.8 & 27.2 & 12.5 & 9.4 & 14.3 & 12.9 \\
\hline$\%$ Normal $^{(8)}$ & 61.7 & 58.8 & 60.1 & 60.1 & 49.8 & 52.3 & 55.4 & 53.9 \\
\hline$\%_{\text {Low }}{ }^{(9)}$ & 16.0 & 15.3 & 9.2 & 12.8 & 37.7 & 38.3 & 30.3 & 33.2 \\
\hline Mean (mg/dL) & 52.1 & 52.9 & 54.9 & 53.6 & 45.3 & 43.5 & 46.9 & 45.9 \\
\hline Median (mg/dL) & 50.3 & 50.3 & 54.2 & 50.3 & 42 & 42 & 45 & 44 \\
\hline
\end{tabular}

Source: US: NHANES 1999-2002; England: HSE 2003. See Table 1 for definitions of income and education groups.

Notes:

(1) HbA1c greater than $6.5 \%$

(2) Blood pressure equal to or greater than $140 \mathrm{~mm} \mathrm{Hg}$ and/or diastolic blood pressure equal to or greater than $90 \mathrm{~mm} \mathrm{Hg}$ and/or taking medication.

(3) $.3 \mathrm{mg} / \mathrm{dL}$ or higher

(4) Between $.1 \mathrm{mg} / \mathrm{dL}$ and $.3 \mathrm{mg} / \mathrm{dL}$

(5) $.1 \mathrm{mg} / \mathrm{dL}$ or lower

(6) $400 \mathrm{mg} / \mathrm{dL}$ or higher

(7) $60 \mathrm{mg} / \mathrm{dL}$ or higher

(8) Between $40 \mathrm{mg} / \mathrm{dL}$ and $60 \mathrm{mg} / \mathrm{dL}$

(9) $40 \mathrm{mg} / \mathrm{dL}$ or lower 
Table 8. Comparisons of Male Self and Biological Reports by SES (ages 40-70 years old) (percentages), by Income Tercile

\begin{tabular}{|c|c|c|c|c|c|c|c|c|}
\hline & \multicolumn{4}{|c|}{ England } & \multicolumn{4}{|c|}{ United States } \\
\hline & Low & Medium & High & All & Low & Medium & High & All \\
\hline \multicolumn{9}{|l|}{ Diabetes } \\
\hline \% prevalence (Self Reports) & 7.5 & 2.8 & 3.2 & 4.4 & 12.7 & 7.7 & 5.2 & 8.6 \\
\hline \% prevalence (Biological Report) ${ }^{(1)}$ & 6.8 & 2.9 & 4.5 & 4.8 & 14.7 & 6.7 & 5.1 & 8.9 \\
\hline \multicolumn{9}{|l|}{ Hypertension } \\
\hline \% prevalence (Self Reports) & 42.7 & 28.8 & 27.9 & 32.0 & 34.0 & 25.0 & 28.7 & 29.3 \\
\hline \% prevalence (Biological Report) ${ }^{(2)}$ & 40.0 & 34.9 & 32.0 & 36.0 & 37.8 & 29.7 & 32.0 & 33.2 \\
\hline \multicolumn{9}{|l|}{ C-reactive Protein } \\
\hline \% High Risk ${ }^{(3)}$ & 34.8 & 23.8 & 23.1 & 27.7 & 39.0 & 31.8 & 26.6 & 32.5 \\
\hline \% Moderate Risk ${ }^{(4)}$ & 40.5 & 39.9 & 39.3 & 39.9 & 37.6 & 40.1 & 35.6 & 37.7 \\
\hline \% Low Risk ${ }^{(5)}$ & 24.7 & 36.3 & 37.6 & 32.3 & 23.4 & 28.1 & 37.8 & 29.9 \\
\hline Mean (mg/dL) & 0.43 & 0.27 & 0.30 & 0.33 & 0.42 & 0.35 & 0.30 & 0.36 \\
\hline Median (mg/dL) & 0.19 & 0.14 & 0.14 & 0.16 & 0.23 & 0.18 & 0.13 & 0.18 \\
\hline \multicolumn{9}{|l|}{ Fibrinogen } \\
\hline \% High Risk ${ }^{(6)}$ & 10.8 & 8.3 & 7.7 & 8.8 & 29.1 & 19.2 & 15.3 & 21.2 \\
\hline Mean (mg/dL) & 311 & 294 & 288 & 297 & 365 & 348 & 335 & 350 \\
\hline Median (mg/dL) & 300 & 290 & 280 & 290 & 358 & 340 & 326 & 342 \\
\hline \multicolumn{9}{|l|}{ HDL Cholesterol } \\
\hline$\%$ High $^{(7)}$ & 24.4 & 26.2 & 33.3 & 27.2 & 13.4 & 10.3 & 14.8 & 12.9 \\
\hline \% Normal ${ }^{(8)}$ & 61.6 & 60.9 & 55.5 & 60.1 & 51.0 & 56.3 & 54.5 & 53.9 \\
\hline \% Low ${ }^{(9)}$ & 14.0 & 12.9 & 11.2 & 12.8 & 35.6 & 33.4 & 30.7 & 33.2 \\
\hline Mean (mg/dL) & 52.9 & 53.2 & 55.2 & 53.6 & 45.9 & 45.2 & 46.6 & 45.9 \\
\hline Median (mg/dL) & 50.3 & 50.3 & 54.2 & 50.3 & 43 & 44 & 45 & 44 \\
\hline $\begin{array}{l}\text { Source: US: NHANES 1999-2002; E } \\
\text { Notes: See notes to Table 4A }\end{array}$ & HSE & & & & & & & \\
\hline
\end{tabular}


Table 9

Family Income Comparisons across the Household Surveys (Ages 55-64 years old)

\begin{tabular}{rrrrr}
\hline & HRS & CPS & ELSA (\$) & FRS (\$) \\
\hline Mean & 80,928 & 68,918 & 45,560 & 47,432 \\
$25^{\text {th }}$ & 30,000 & 27,756 & 18,271 & 21,926 \\
$50^{\text {th }}$ & 56,192 & 52,000 & 33,256 & 37,106 \\
$75^{\text {th }}$ & 97,000 & 88,112 & 54,505 & 59,903 \\
$90^{\text {th }}$ & 167,400 & 136,500 & 85,109 & 89,286 \\
$95^{\text {th }}$ & 228,188 & 180,400 & 117,126 & 115,096 \\
\hline
\end{tabular}

Sample-Families with a head between the ages of 55-64 years old. All data are weighted. 
Table 10

Comparing CPS and HRS Measures of Family Income

\begin{tabular}{lrrr}
\hline & CPS & HRS & Difference \\
\hline Total Family Income & 68,918 & 80,928 & 12,010 \\
Total Capital Income & 8,663 & 20,733 & 12,070 \\
Self Employment Income & 4,400 & 13,268 & 8,868 \\
Other Income & 4,263 & 7,465 & 3,202 \\
\hline
\end{tabular}

Sample-Families with a head between the ages of 55-64 years old. All data are weighted. 
Table 11A

Poor Health and Work by Income Quartile_England

\begin{tabular}{ccccccccc}
\hline & \multicolumn{3}{c}{ Fraction in Poor Health } & \multicolumn{4}{c}{ Fraction Not Working } \\
& \multicolumn{3}{c}{ Income Quartile within Age } & \multicolumn{3}{c}{ Income Quartile within Age } \\
Age & 1 & 2 & 3 & 4 & 1 & 2 & 3 & 4 \\
\hline $50-53$ & 0.313 & 0.164 & 0.127 & 0.060 & 0.336 & 0.075 & 0.037 & 0.030 \\
$54-57$ & 0.360 & 0.258 & 0.098 & 0.117 & 0.409 & 0.209 & 0.079 & 0.067 \\
$58-61$ & 0.331 & 0.270 & 0.162 & 0.099 & 0.697 & 0.426 & 0.211 & 0.184 \\
$62-65$ & 0.354 & 0.380 & 0.233 & 0.140 & 0.838 & 0.729 & 0.434 & 0.442 \\
$66-69$ & 0.339 & 0.382 & 0.274 & 0.130 & 0.952 & 0.878 & 0.879 & 0.642 \\
\hline
\end{tabular}

Table 11B

Proportion in Poor Health by Work Status

(Low Education Group-Bottom Income Quartile)

\begin{tabular}{ccc}
\hline & \multicolumn{2}{c}{ Work Status } \\
Age & Working & Not Working \\
\hline $50-53$ & 0.238 & 0.800 \\
$54-57$ & 0.077 & 0.850 \\
$58-61$ & 0.000 & 0.571 \\
$62-65$ & 0.143 & 0.463 \\
$66-69$ & 0.000 & 0.354 \\
\hline
\end{tabular}


Table 12A

Poor Health and Work by Income Quartile_-United States

\begin{tabular}{ccccccccc}
\hline & \multicolumn{3}{c}{ Fraction in Poor Health } & \multicolumn{4}{c}{ Fraction Not Working } \\
& \multicolumn{3}{c}{ Income Quartile within Age } & \multicolumn{3}{c}{ Income Quartile within Age } \\
Age & 1 & 2 & 3 & 4 & 1 & 2 & 3 & 4 \\
\hline $50-53$ & 0.357 & 0.152 & 0.102 & 0.056 & 0.293 & 0.084 & 0.058 & 0.041 \\
$54-57$ & 0.419 & 0.184 & 0.115 & 0.069 & 0.391 & 0.150 & 0.108 & 0.071 \\
$58-61$ & 0.430 & 0.213 & 0.146 & 0.075 & 0.544 & 0.313 & 0.224 & 0.143 \\
$62-65$ & 0.438 & 0.239 & 0.166 & 0.098 & 0.746 & 0.622 & 0.521 & 0.346 \\
$66-69$ & 0.418 & 0.275 & 0.200 & 0.107 & 0.838 & 0.772 & 0.734 & 0.738 \\
\hline
\end{tabular}

Table 12B

Proportion in Poor Health by Work Status

(Low Education Group-Bottom Income Quartile)

\begin{tabular}{rcc}
\hline & \multicolumn{2}{c}{ Work Status } \\
Age & Working & Not Working \\
\hline $50-53$ & 0.265 & 0.687 \\
$54-57$ & 0.273 & 0.704 \\
$58-61$ & 0.291 & 0.705 \\
$62-65$ & 0.314 & 0.566 \\
$66-69$ & 0.290 & 0.496 \\
\hline
\end{tabular}


Table 13

Probits for Probability of Stopping Work

\begin{tabular}{lcc}
\hline Stopwork & $\mathrm{dF} / \mathrm{dx}$ & $\mathrm{z}$ \\
\hline Middle education & -.406 & $(2.83)$ \\
High education & -.286 & $(1.77)$ \\
Male & -.041 & $(2.07)$ \\
Age in 1998 & .009 & $(3.26)$ \\
Middle education*Age in 1998 & .009 & $(2.67)$ \\
High education*Age in 1998 & .005 & $(1.56)$ \\
Married/cohab in 1998 & .044 & $(2.04)$ \\
Hits State Pension Age between 1998 and 2002 & .189 & $(5.51)$ \\
SRH = good & -.130 & $(2.76)$ \\
SRH = very good & -.230 & $(4.46)$ \\
SRH = excellent & -.202 & $(4.06)$ \\
Onset of diabetes/HBP/angina & .041 & $(1.42)$ \\
Onset of heart attack/stroke & .221 & $(3.01)$ \\
\hline
\end{tabular}

Source: HSE (1998) and ELSA. 
Table 14

\% Change in Family Income

\begin{tabular}{lccrc}
\hline \% Change in Income & $\mathrm{dF} / \mathrm{dx}$ & $\mathrm{z}$ & $\mathrm{dF} / \mathrm{dx}$ & $\mathrm{dF} / \mathrm{dx}$ \\
\hline Middle education & .126 & $(0.78)$ & .121 & $(0.75)$ \\
High education & -.061 & $(0.39)$ & -.032 & $(0.21)$ \\
Male & .014 & $(0.91)$ & .029 & $(1.82)$ \\
Age in 1998 & -.002 & $(0.94)$ & -.005 & $(1.98)$ \\
Middle education*Age in 1998 & -.002 & $(0.87)$ & -.002 & $(0.84)$ \\
High education*Age in 1998 & .001 & $(0.44)$ & .001 & $(0.23)$ \\
Married/cohab in 1998 & .014 & $(0.78)$ & .017 & $(0.95)$ \\
SRH = good & .070 & $(1.39)$ & .057 & $(1.13)$ \\
SRH = very good & .110 & $(2.27)$ & .092 & $(1.90)$ \\
SRH = excellent & .088 & $(1.79)$ & .069 & $(1.41)$ \\
Hits State Pension Age between 1998 and 2002 & & & .159 & $(5.08)$ \\
Hits State Pension Age*Stops Work & & & -.169 & $(5.31)$ \\
Onset of diabetes/HBP/angina & -.007 & $(0.33)$ & -.004 & $(0.16)$ \\
Onset of heart attack/stroke & -.187 & $(3.30)$ & -.169 & $(3.00)$ \\
Cons & -.393 & $(3.32)$ & -.248 & $(1.85)$ \\
\hline
\end{tabular}

Source: HSE (1998) and ELSA. 
Table 15

Health Outcomes by Net Financial Wealth

\begin{tabular}{|c|c|c|c|c|c|c|c|}
\hline $\begin{array}{l}\text { Net financial } \\
\text { wealth quintile/ } \\
\text { range (\$`000’s) }\end{array}$ & Diabetes & Hypertension & Heart Attack & Stroke & Heart Disease & Lung Disease & Cancer \\
\hline \multicolumn{8}{|l|}{ England } \\
\hline $1:<0.8$ & 9.8 & 37.6 & 11.5 & 6.0 & 18.2 & 10.6 & 5.5 \\
\hline 2: $0.8-14.4$ & 7.7 & 36.8 & 6.9 & 3.0 & 16.4 & 6.3 & 2.7 \\
\hline 3: $14.4-46.4$ & 7.0 & 35.9 & 4.8 & 1.5 & 10.7 & 4.9 & 2.7 \\
\hline 4: $46.4-112.7$ & 5.6 & 32.9 & 5.0 & 2.8 & 9.4 & 5.1 & 2.5 \\
\hline 5: >112.7 & 5.6 & 29.4 & 3.7 & 1.5 & 8.5 & 2.3 & 4.6 \\
\hline \multicolumn{8}{|l|}{ United States } \\
\hline $1:<0.5$ & 21.0 & 54.2 & 15.4 & 5.3 & 25.9 & 13.1 & 4.5 \\
\hline 2: $0.5-10.5$ & 16.5 & 46.0 & 10.0 & 6.5 & 17.9 & 6.4 & 6.0 \\
\hline 3: $10.5-42.3$ & 10.6 & 46.5 & 5.6 & 3.2 & 14.5 & 5.9 & 9.7 \\
\hline 4: $42.3-146.9$ & 14.5 & 47.6 & 5.0 & 2.5 & 16.3 & 6.3 & 6.8 \\
\hline 5: >146.9 & 10.2 & 40.5 & 4.8 & 2.7 & 15.8 & 3.0 & 9.2 \\
\hline
\end{tabular}

Sources: English data is from first wave of ELSA. American data is from the 2002 wave of the HRS. 


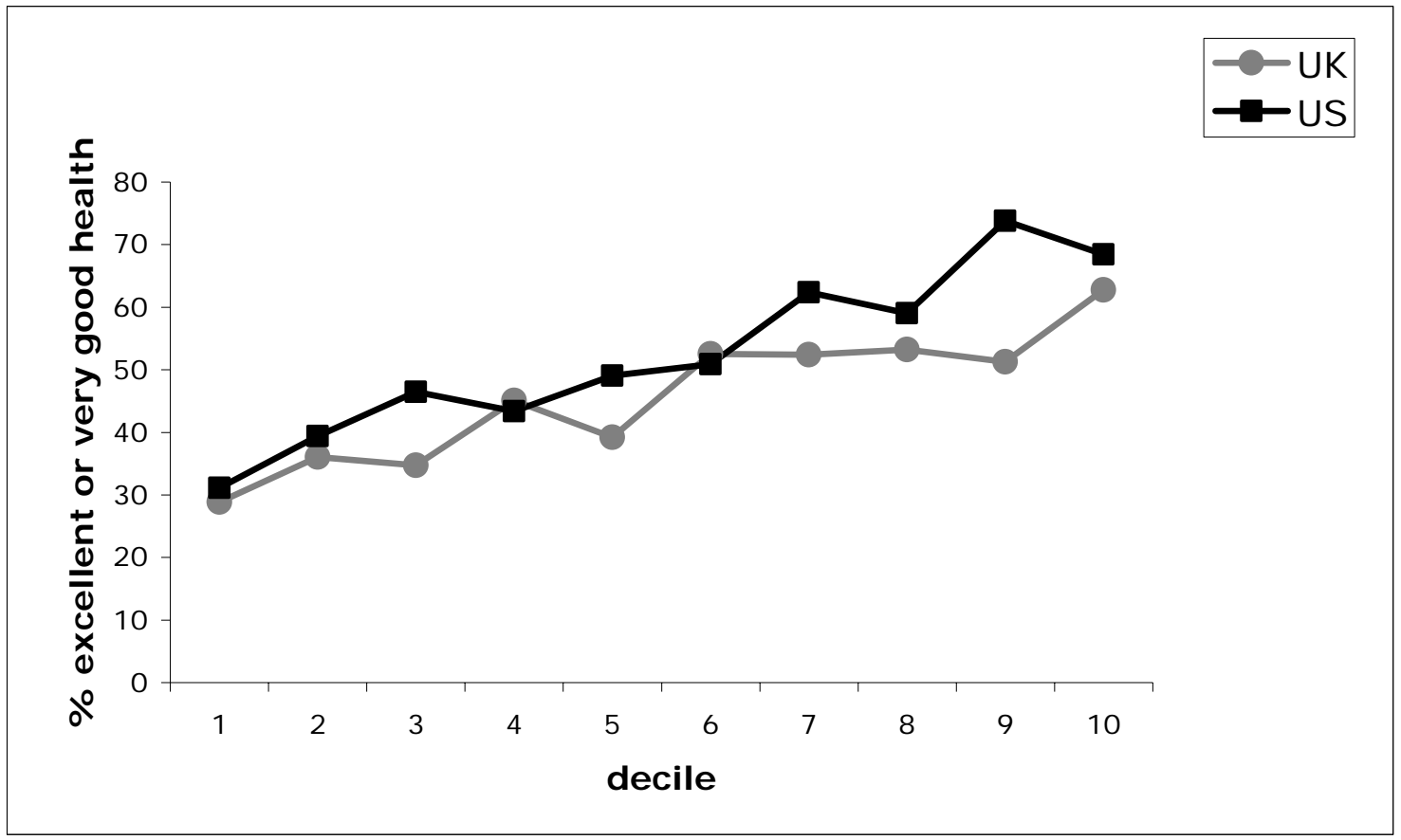

Fig. 1A. \% in Excellent or Very Good Health by Income Deciles.

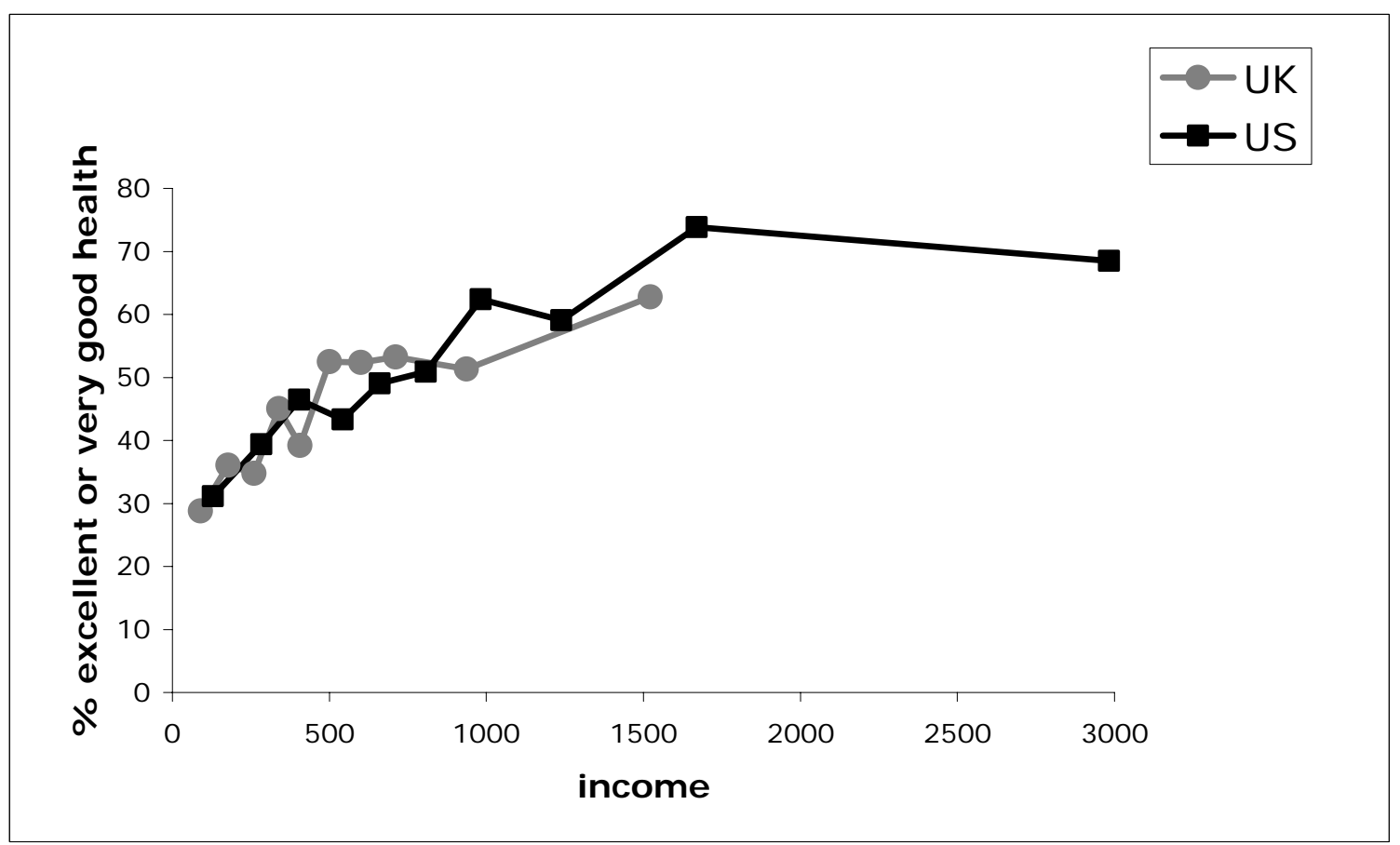

Fig. 1B. \% in Excellent or Very Good Health by Income. 


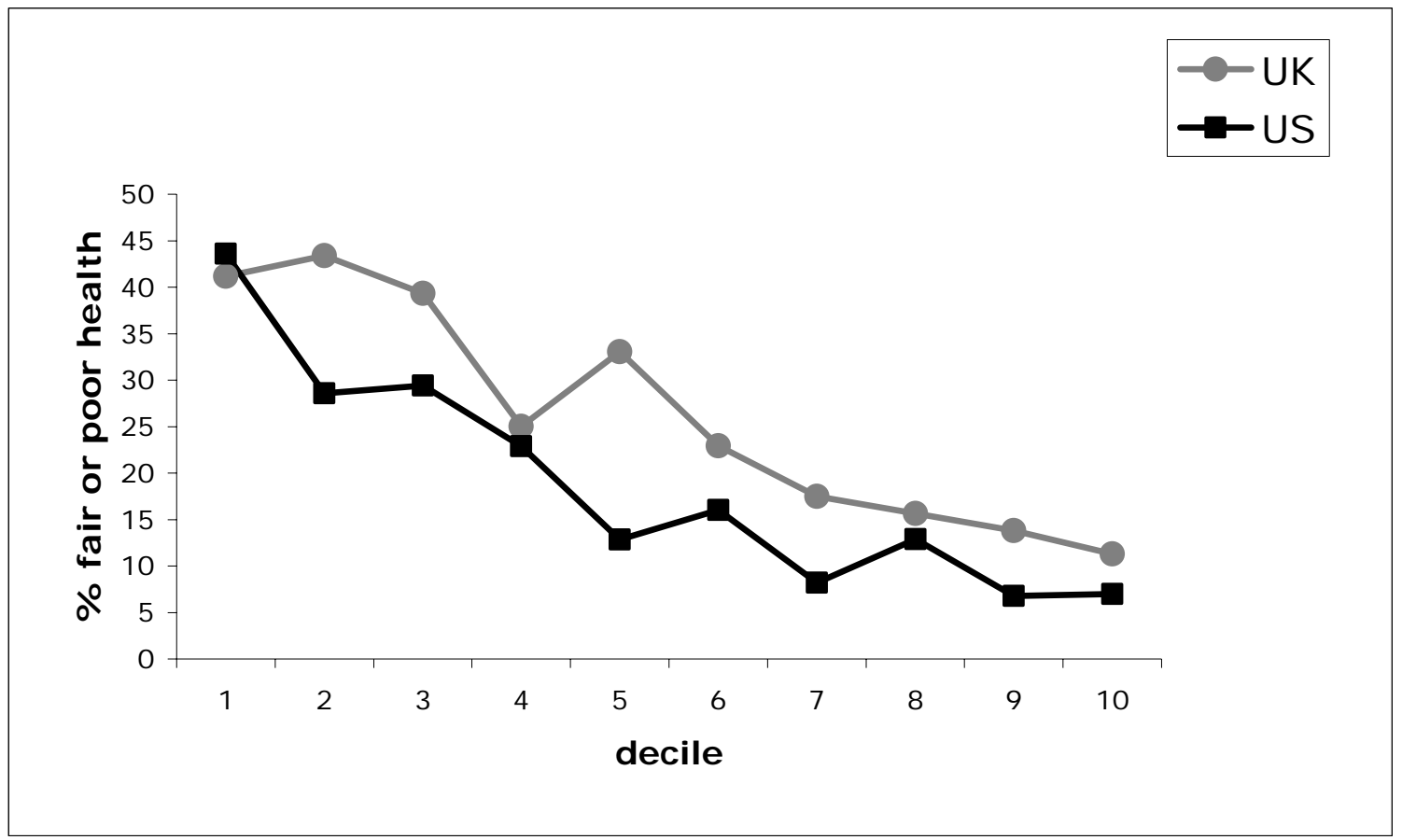

Fig. 2A. \% in Fair or Poor Health by Income Deciles.

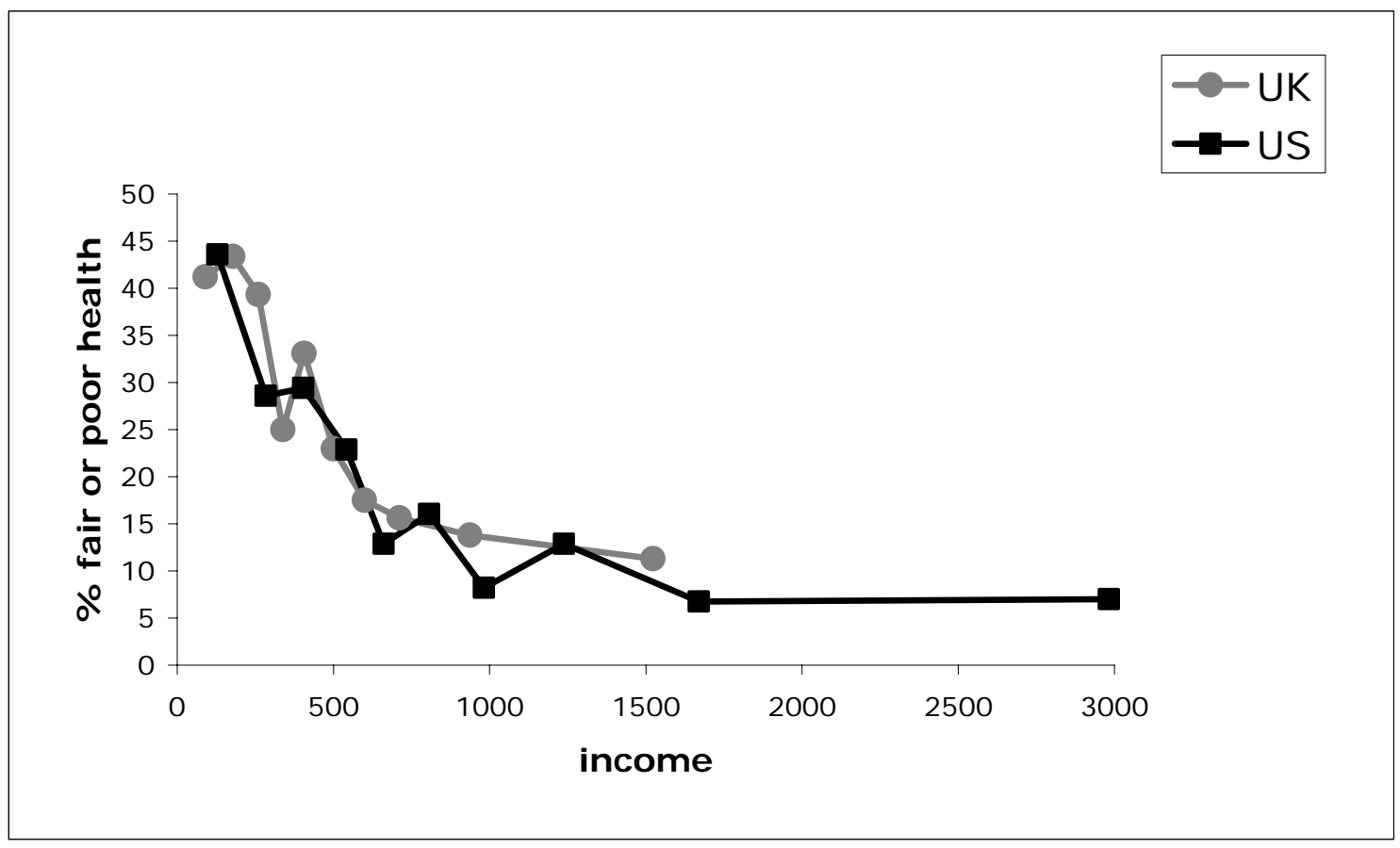

Fig. 2B. \% in Fair or Poor Health by Income. 


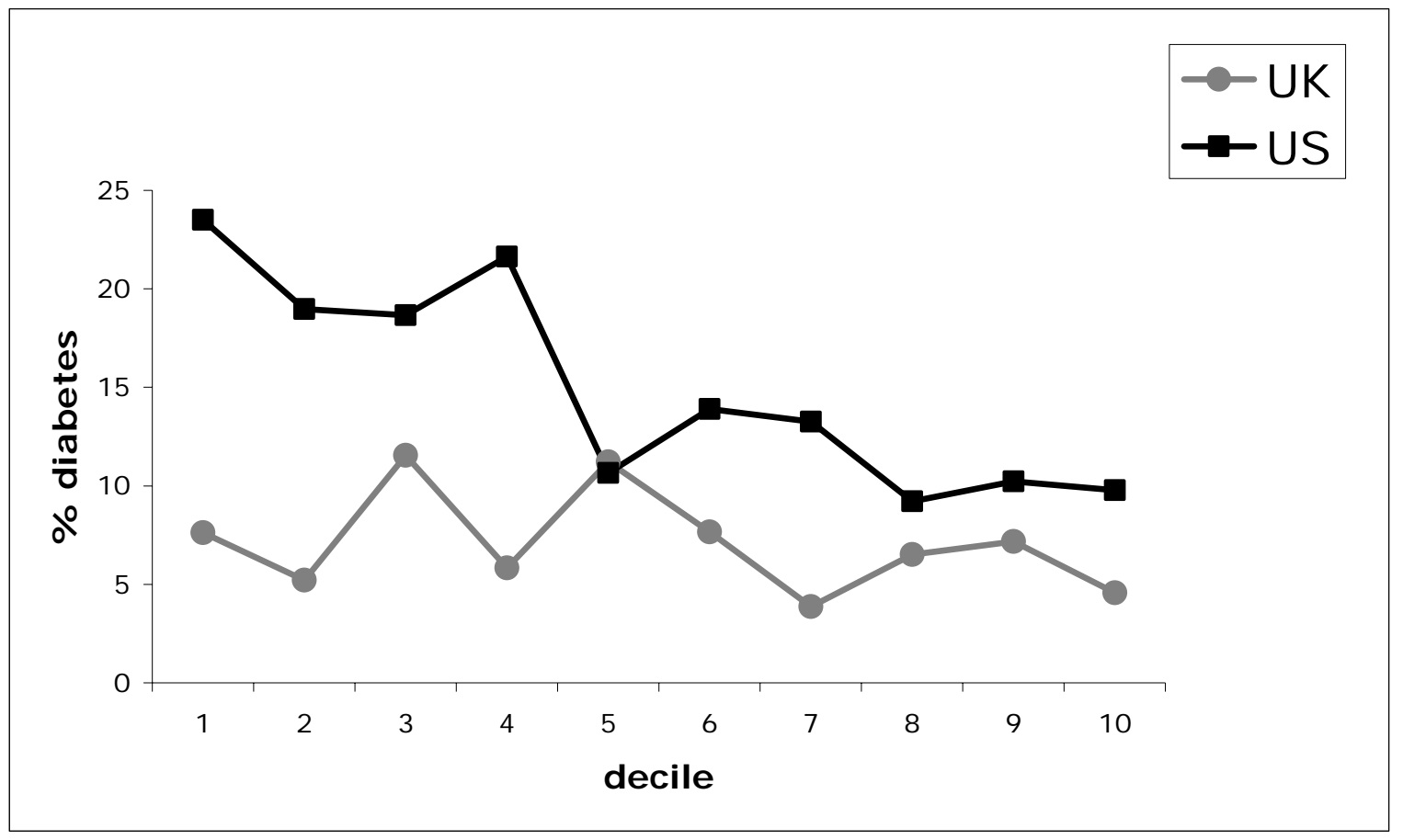

Fig. 3A. \% with Diabetes by Income Deciles.

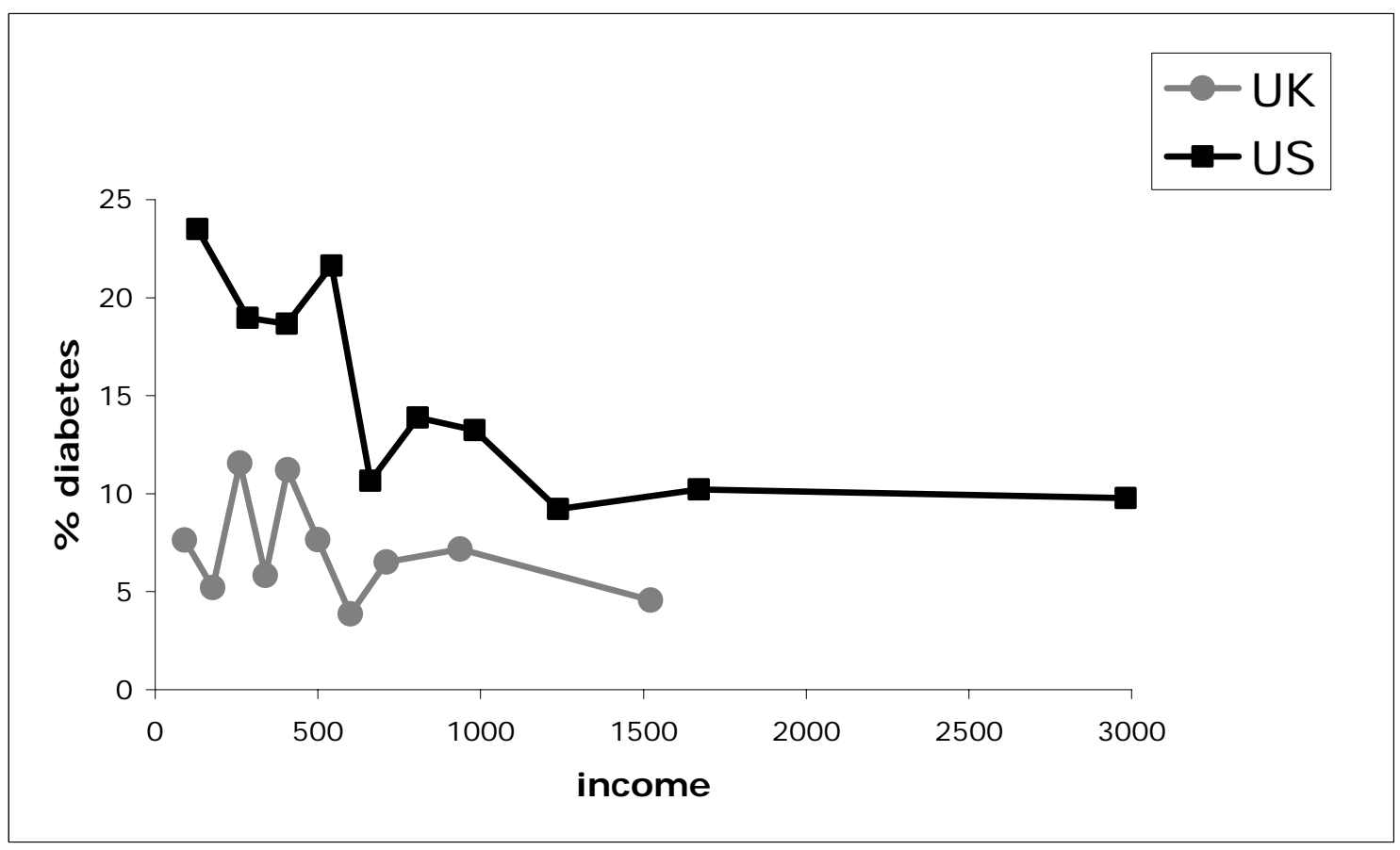

Fig. 3B. \% with Diabetes by Income. 


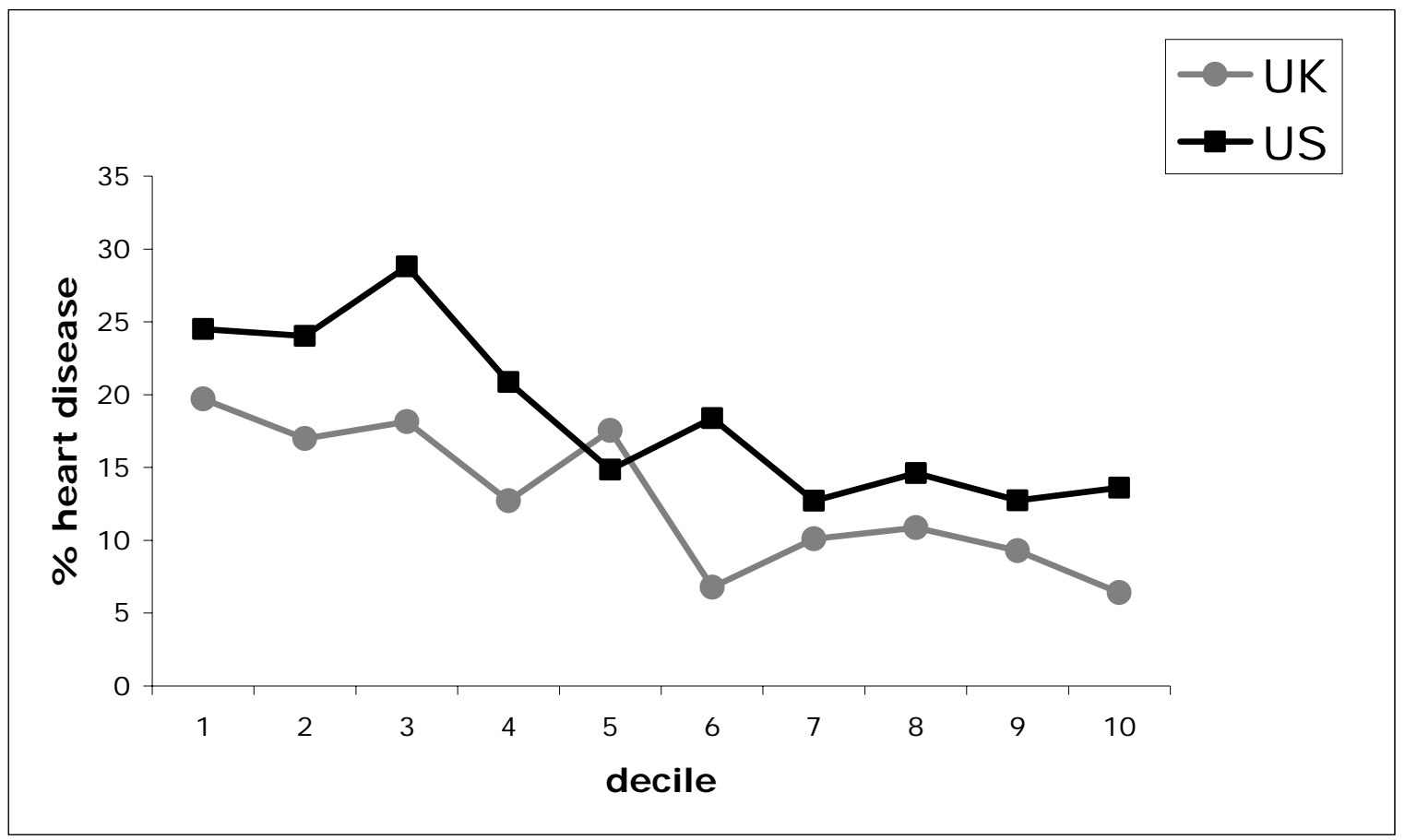

Fig. 4A. \% with Heart Disease by Income Deciles.

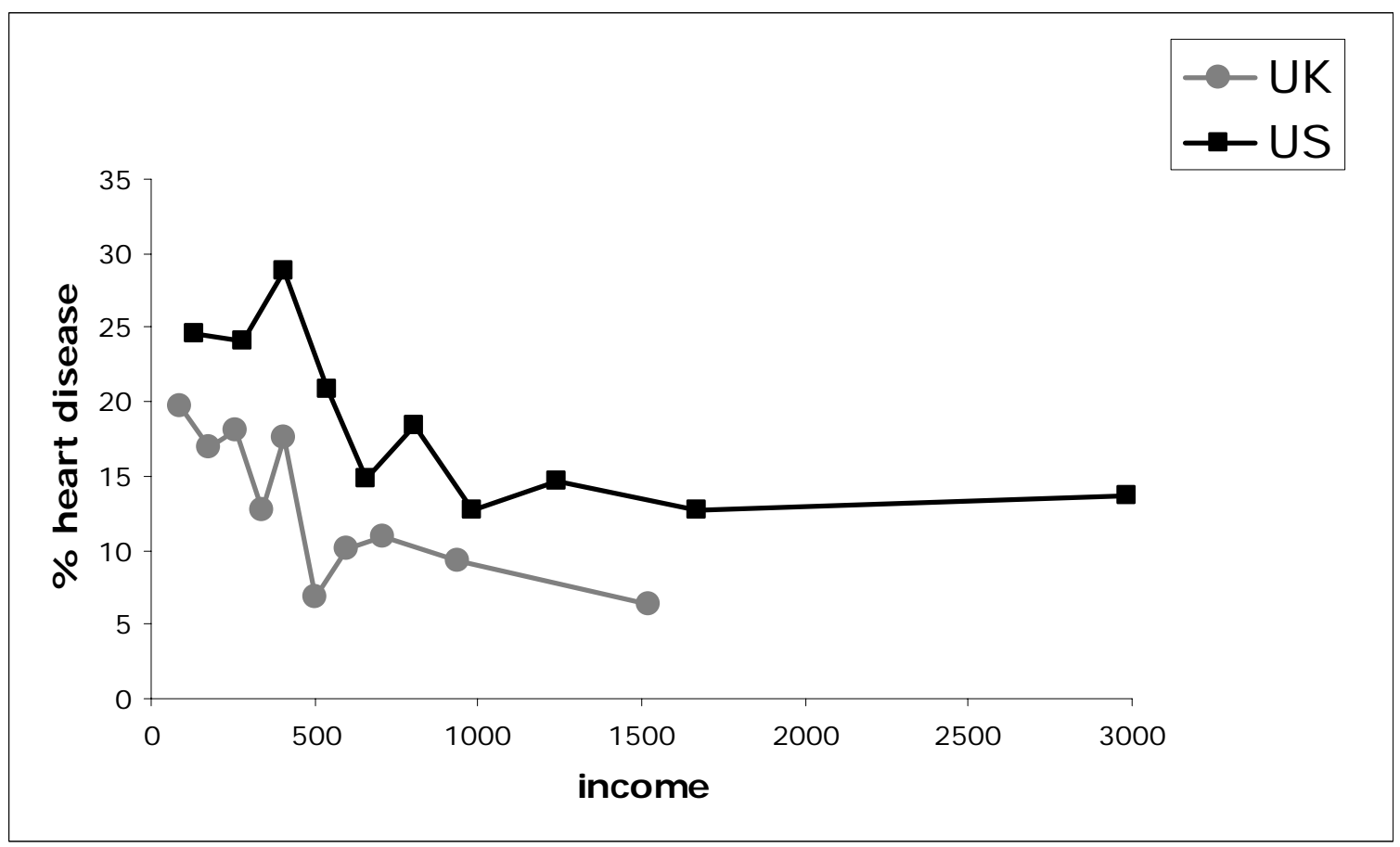

Fig. 4B. \% with Heart Disease by Income. 


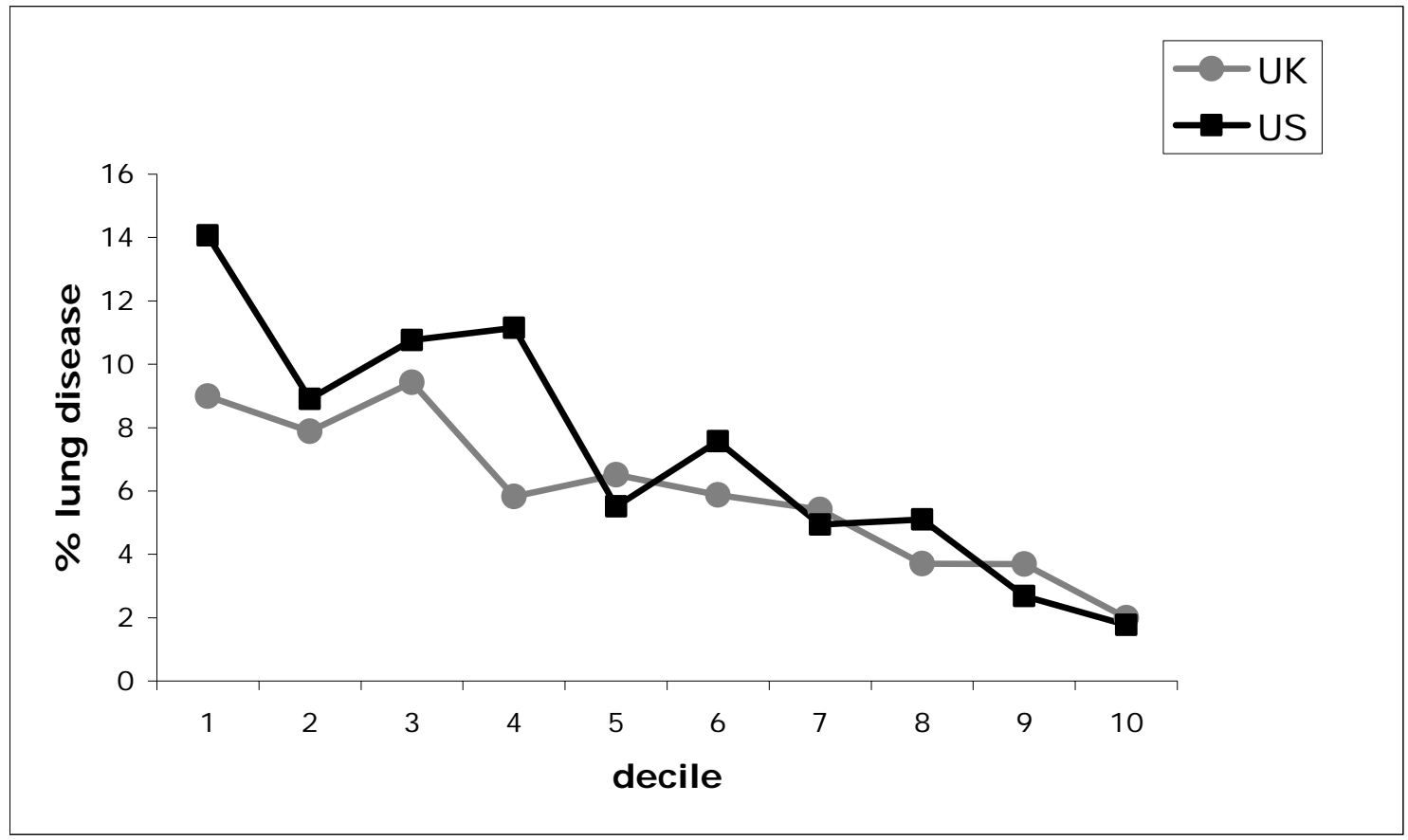

Fig. 5A. \% with Lung Disease by Income Deciles.

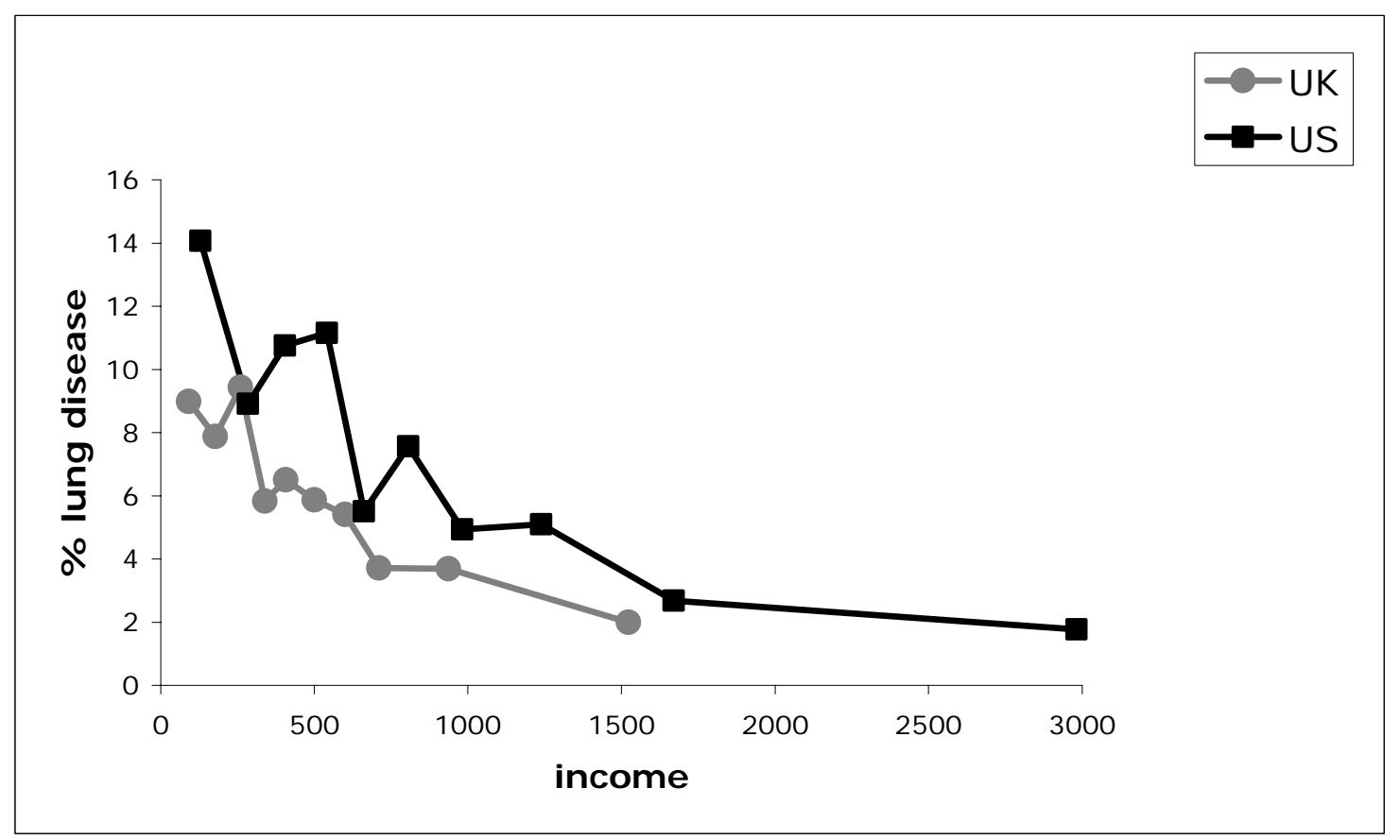

Fig. 5B. \% with Lung Disease by Income. 